\title{
Fisheries restoration potential for a large lake ecosystem: using ecosystem models to examine dynamic relationships between walleye, cormorant, and perch
}

\author{
Andrea M. McGregor ${ }^{1,2}$, Christopher L. Davis ${ }^{3}$, Carl J. Walters ${ }^{4}$ and Lee Foote ${ }^{1}$
}

\begin{abstract}
Increased population sizes of Double-crested Cormorants (Phalacrocorax auritus) and small-bodied ( $<15 \mathrm{~cm}$ total length) yellow perch (Perca flavescens) have occurred at Lac la Biche, Alberta, Canada, since fisheries collapsed the walleye (Sander vitreus) population. A walleye restoration program was introduced in 2005, but uncertainty around the ecosystem's response to management made it difficult to evaluate program success. This study used 40 variations of Ecopath with Ecosim models representing ecosystem conditions over 200 years to test the potential for multiple attractors, i.e., possible ecosytem states, in a large lake ecosystem. Results suggest that alternate stable states, defined by walleye-dominated and cormorant-dominated equilibriums, existed in historical models $(1800,1900)$, whereas contemporary models $(1965,2005)$ had a single cormorant-dominated attractor. Alternate stable states were triggered by smaller perturbations in 1900 than in 1800, and model responses were more intense in 1900, suggesting a decline in system resilience between model periods. Total prey biomass consumed by walleye was up to four times greater than the biomass consumed by cormorants in historical models, but dropped to $10 \%$ of cormorant consumption in 2005 models. Differential size-selection pressures of cormorants and walleye on yellow perch provided strong feedback that stabilized each state. These results provide important theoretical support for alternate stable states as well as practical insights for restoration of large lake ecosystems affected by human induced overharvest of top-level fish predators.
\end{abstract}

Key Words: alternate stable states; cormorant; ecosystem modeling; Lac la Biche; restoration; walleye; yellow perch

\section{INTRODUCTION}

Tophic cascades along with cultivation-depensation effects can cause alternate stable states (ASSs) in aquatic ecosystems following the removal of top predators (Walters and Kitchell 2001, Daskalov et al. 2007, Carpenter et al. 2008). Despite the frequent overharvest of predators in many freshwater ecosystems worldwide, there is little research describing ASSs in this context (but see Persson et al. 2007, Carpenter et al. 2011, Ellis et al. 2011). Over the last 30 years several species of piscivorous birds have increased in abundance (Weseloh et al. 2002), most obviously Double-crested Cormorant (cormorant; Phalacrocorax auritus) populations in North America and Great Cormorant (Phalacrocorax carbo) populations in Europe. Expanding cormorant populations are regularly linked to declines in important fisheries such as the yellow perch (perch; Perca flavescens) fishery in the Les Cheneaux Islands region of Lake Huron (Fielder 2008), and both perch and walleye (Sander vitreus) fisheries in Oneida Lake in New York, USA (Rudstam et al. 2004). In other areas, cormorant populations expanded after important fisheries collapsed, such as the alewife (Alosa pseudoharengus) fisheries in south-central Connecticut, USA (Dalton et al. 2009) and perch fisheries in Dore Lake, Saskatchewan, Canada (Barks et al. 2010). Where cormorants caused fishery reductions, cormorant control has generally improved prey fish survival enough to allow their recovery (Fielder 2010). When management has not achieved the desired results, ASSs could help explain observed dynamics in cormorant-fishery conflicts and help progress in recovery or restoration efforts.

The restoration potential and approach require an understanding of how a system is likely to respond to a disturbance. Three main conceptual models describing equilibrium dynamics of ecosystems are generally applicable to disturbance and restoration ecology: continuum models, threshold models, and ASS models (Hobbs and Suding 2009). A system exhibiting continuum dynamics is expected to recover to its predisturbance state along a predictable successional pathway that is steady, directional, and driven by strong negative feedback mechanisms (Odum 1969). In such cases, restoration should proceed unassisted, although management interventions can be used to initiate, assist, or speed up succession (Hobbs and Suding 2009). Threshold models describe system dynamics in which a relatively small change in a controlling variable causes a large shift in ecosystem state (Hobbs and Suding 2009). ASS models (Scheffer et al. 2001, Scheffer 2009) describe a specific type of threshold model in which a critical level of a controlling variable is surpassed, resulting in changes in system feedbacks that alter the trajectory of the system's development. Restoring a system following an ASS transition can be difficult because of hysteresis (Suding et al. 2004). In such systems, management focused on affecting change in the factors or processes that caused the initial switch might be insufficient to achieve recovery, management efforts might not address the real problem, or more intensive effort might be required.

Over most of the last 50 years the lake ecosystem of Lac la Biche, Alberta, Canada, has existed in a state of extremely low walleye biomass resulting from centuries of overharvest. In the last 25 years there has been an exponential increase in the number of fish-eating birds, dominated by cormorants, and a noticeable change in the size and abundance of forage fish, namely perch. The result of these, among other recent changes to the lake

${ }^{1}$ University of Alberta, Department of Renewable Resources, ${ }^{2}$ Alberta Environment and Sustainable Resource Development, ${ }^{3}$ Ontario Ministry of Natural Resources, ${ }^{4}$ UBC Fisheries Centre 
ecosystem such as cultural eutrophication (Schindler et al. 2008), has been the development of a system that is unable to satisfy social demands for harvestable-sized walleye as well as other goods and services. In 2005, Alberta Environment and Sustainable Resource Development responded to these concerns by introducing a long-term lake restoration project focused on commercial and recreational fishery reductions, walleye stocking, and cormorant control as suitable methods for recovering walleye in the lake and for improving the overall size structure of the fish community. Although management initiatives are under way, the potential for restoration to a walleye-dominated equilibrium remains unclear.

In this study, we focus on describing the dynamic relationships between walleye, perch, and cormorants at Lac la Biche to improve our understanding of the long-term restoration potential for walleye. We used a series of ecosystem models representing an historical walleye-dominated system, a contemporary cormorant-dominated system, and a transitional perchdominated system to assess the potential for alternate attractors at Lac la Biche. Models representing 4 eras over the last 210 years were used to explore the size and type of disturbance required to trigger ASSs, as well as the restoration potential given recent walleye stocking and cormorant control efforts.

\section{METHODS}

\section{Study area}

Lac la Biche is located in northeastern Alberta, Canada, along the northern edge of the hamlet of Lac la Biche. It is one of the province's largest lakes at more than 22,000 ha. Lac la Biche is a eutrophic lake (chlorophyll $\mathrm{a}=16 \mathrm{mg} / \mathrm{m}^{-3}$ in the east basin and $10 \mathrm{mg} / \mathrm{m}^{-3}$ in the west basin; Schindler et al. 2008) with a drainage basin of more than $4000 \mathrm{~km}^{2}$ and an average depth of only 8.3 $\mathrm{m}$. The lake has two distinct basins: the west basin is deep (maximum $21.3 \mathrm{~m}$ ) with little bottom structure, whereas the east basin is similarly sized but is shallow (maximum $12.2 \mathrm{~m}$ ) with many islands, rock bars, and changes in water depth (Mitchell and Prepas 1990).

\section{Modeling approach}

The Lac la Biche ecosystem was modeled using Ecopath with Ecosim software version 6.2.0.620 (Pauly et al. 2000, Christensen et al. 2008). The Ecopath model uses a series of linear equations to balance the energy gains and losses for each biological component of an ecosystem over a defined time period, usually one year. The resulting mass balance condition allows for the estimation of initial, static flows of energy or nutrients between trophic levels, and it provides a means for estimating the relative importance of individual species/ecological guilds or ecological processes such as selective predation and targeted fisheries (Christensen et al. 2008). Production by each functional group is calculated as the sum of catches, predation mortality, biomass accumulation, net migration, and other mortality. This equation is more commonly expressed using the following parameters: biomass (B) in tonnes per square kilometer, production/biomass $(\mathrm{P} / \mathrm{B})$ per year, consumption/biomass $(\mathrm{Q} / \mathrm{B})$ per year, and ecotrophic efficiency (EE), i.e., the proportion of production that is utilized by the system for predation or export (Christensen et al. 2008). If one of the four basic parameters (B, P/B, Q/B, EE) is not entered, Ecopath can estimate that parameter given the input of the following secondary parameters: fisheries catches $(\mathrm{Y})$, net migration (M), biomass accumulation (BA), food assimilation (A), or diet composition (DC). Mass balance is achieved when the consumption by each functional group is balanced by the sum of their production, respiration, and estimates of unassimilated food. Model units were $t / \mathrm{km}^{2}$ for biomasses and $\mathrm{t} \cdot \mathrm{km}^{-2} \cdot \mathrm{year}^{-1}$ (wet weight) for flows of organic matter, where $t$ refers to a metric tonne.

The complementary dynamic simulation tool, Ecosim (Walters et al. 1997), uses a combination of differential equations for predicting changes in flow rates as functions of prey and predator abundances for each trophic link. Species that show strong trophic ontogeny in feeding and/or size-selective harvesting and vulnerability to predation are modeled through age stanzas that use monthly difference equations to predict changes in age and size structure (Walters et al. 2009). Parameter values for other modeled groups generally reflected characteristics of the adult population because adults dominated the biomass of each group. To achieve mass balance, we considered how the inclusion of smaller and younger individuals would affect each variable and parameter. Values for P/B were most commonly changed to achieve mass balance; changes were based on shifts in the expected or observed relative abundances of smaller/younger individuals in a population. For a detailed description of the Ecopath with Ecosim software package, see Christensen et al. (2008).

ASSs are produced in Ecosim under very particular sets of conditions, and the domain of parameter combinations that will result in multiple equilibria is usually very small. The cultivationdepensation effect resulting in multiple equilibria typically appears in Ecosim under the general conditions described by Walters and Kitchell (2001): there must be (1) a dominant predator that is efficient at capturing all its prey species and (2) at least one of these prey must have a diet composition that can compete with or feed upon the prey of the juvenile of the dominant species, and also shows a large positive numerical response when the dominant species is reduced. It is also possible to get multiple equilibria through "overcompetition," where the negative effect of each species on productivity of the other species is greater than the negative effect of the species on itself; in this case, each competitive equilibrium involves eventual extinction of whichever species starts out lower.

\section{Model development}

Forty Ecopath models were used to capture variability in ecosystem scenarios over the study period and to explore how different ecosystem configurations affected the system's response to disturbance. Models differed from one another in biomass and diet composition. Each model was balanced using a different combination of parameter values from a range representing published variability for each species. Walleye-dominated states were represented by 20 models of the historical ecosystem representing the years 1800 and 1900. Models for $1800(n=10)$ depicted possible conditions prior to European settlement, when the walleye population was assumed to be only lightly disturbed. Parameters for 1800 were compiled from scientific literature, historical sources, anecdotal and anthropological studies, expert opinion, and data from similar systems. See McGregor (2014) for a detailed description of how the 1800 model was parameterized. Models for $1900(n=10)$ describe a range of ecosystem conditions 
expected after 100 years of subsistence harvest by the local aboriginal community, the fur trade post, and the Roman Catholic Mission but prior to the development of a formal commercial fishing industry. Few data and little information were available to parameterize a unique model for 1900 , so conditions were estimated from simulated outputs based on the 1800 model. Specifically, model inputs for 1900 combined expert knowledge with Ecosim exports to tune a balanced 1800 model to a time series of 112 years of fisheries catch estimates for lake whitefish (Coregonus clupeaformis), walleye, northern pike (Esox lucius), and white sucker (Catostomus commersonii). Vulnerability values used in fitting the time series ranged from 1.0 to 4.0 and were similar to the values used across trophic control scenarios during later hypothesis testing. Exported biomass and diet composition predictions from the fitted 1800 model were used in the 1900 models. Exports from the temporal simulation were used in the initial parameterization of the 1900 models, but to achieve mass balance the remaining model parameters were altered within the range of values compiled for the 1800 models. A description of the modeled groups and the range of parameter values represented by the models are included in Appendix 1 (Tables A1.1 to A1.7). For a detailed description of data sources and methodologies, see McGregor (2013a).

Contemporary ecosystem variability was captured in 20 models representing 2 different system states: a cormorant-dominated state $(2005 ; \mathrm{n}=12)$ and a transition state where both cormorants and walleye were present at extremely small biomasses (1965; $\mathrm{n}$ $=8$ ). More models were available for the cormorant-dominated state because models could be developed using the range of variability of field data. Originally 10 transition models were created, but there was too much overlap between 2 models to justify treating them as unique models.

The transition model was parameterized following the same process used for the 1900 models. A balanced Ecopath model for 1900 was tuned to trends in biomass $\left(\mathrm{t} \cdot \mathrm{km}^{-2}\right)$ and fisheries catch $\left(\mathrm{t} \cdot \mathrm{km}^{-2} \cdot \mathrm{yr}^{-1}\right)$ estimates for the years between 1900 and 2009. Predictions of biomass and diet composition for 1960, 1965, and 1970 were exported from Ecosim and used to guide the initial parameterization of the transition model. Where parameter changes were needed to achieve mass balance, they were bounded by the range of values used in other contemporary models (2005). Input parameters for the cormorant-dominated models (2005) are mainly from unpublished field data from Lacla Biche collected between 2003 and 2005, as well as estimates from biologists with knowledge of the lake. Where local data were not available, the contemporary models were parameterized using data or literature values from other systems. Main data sources and estimation methods for the 2005 models are described in McGregor (2013a). A description of the modeled groups and the range of parameter values represented by the models are included in Appendix 1 (Tables A1.1 to A1.7). A representative example of the modeled ecosystem for each era showing pathways of energy flow between functional groups is included in Appendix 2 (Figs. A2.1 to A2.4).

\section{Hypothesis evaluation with Ecosim}

Ecosim was used for assessing the possible existence of ASSs at Lac la Biche and for describing the relationship between the size and nature of a change in fishing effort and the intensity of the ASS response. In all models, cormorants were included as a fishery to allow annual reductions in the cormorant population resulting from control activities, i.e., adult culling. Fishing disturbances were modeled by changing the Ecopath base fishing effort in each Ecosim scenario. All Ecosim scenarios were run following the same general procedure. First, we allowed the model to run for 15 years to ensure no rapid change in biomasses from the baseline state. At year 15, we changed the fishing effort for cormorants, adult walleye, or perch for a period of 5 years to cause a shortduration perturbation in the system. After 5 years the fishing effort was returned to baseline. The model was run for an additional 80 years to see if the groups returned to baseline, cycled around the baseline, or moved to an alternate state with no indication of a return to baseline (ASS; Fig. 1). An outcome was considered an ASS if the largest positive or negative change in relative biomass was at least 0.2 times the baseline and the majority of functional groups maintained a stable biomass over the 100-year simulation. A 100-year simulation was long enough to allow stability over many generations of the entire community (Connell and Sousa 1983). Continuum dynamics and cycling were both reported as a negative ASS result.

Trophic control type, i.e., top-down, bottom-up, wasp-waist, or mixed, was modeled in Ecosim through changes in "vulnerabilities" describing the effect of an increase in the biomass of a predator on the predation mortality of its prey (Christensen et al. 2008). Top-down control was modeled by setting larger vulnerabilities for predators $(\mathrm{v}=3.0)$, bottom-up control by setting small values for low trophic-level groups $(\mathrm{v}=1.0)$, and wasp-waist (mixed control) by setting lower values for invertebrate and zooplankton groups ( $\mathrm{v}=1.0$; Coll et al. 2006). Ecopath default vulnerabilities of 2.0 were maintained in tests of topdown/bottom-up or "mixed control" and for all functional groups not assigned a vulnerability value of 1.0 or 3.0 (Table 1). Conservative vulnerabilities ( $\mathrm{v}=1.0$ to 3.0 ) were used because large values are known to cause instability in models (Araujo et al. 2006, Christensen et al. 2008), and we wanted to be confident that an ASS response was triggered by the disturbance and not by model instability. A similar process was used by Feng et al. (2006) in an assessment of ASSs across a sample of 26 published Ecopath models. For all Ecosim model runs, values in the "Group Info" tab were maintained at recommended defaults, except the feeding time adjustment rate of the four bird groups was reduced from 1.0 to 0.5 . Values were held constant for all model runs to allow consistent testing for ASSs and because we did not have sufficient information to justify changes to these groups and did not want to introduce unnecessary error to model simulations.

\section{Assessment of ASSs}

In total, 640 theoretical scenarios were run to assess the existence of ASS under different assumptions of ecosystem conditions, disturbance levels, and trophic control. An outline of the scenarios can be found in Table 2, objective 1. For each scenario, fishing effort was increased to $10 \mathrm{X}$ the Ecopath baseline for walleye, cormorants, and perch, and also to $100 \mathrm{X}$ for perch. The presence or absence of an ASS was reported. For each model era, i.e., 1800, 1900, 1965, and 2005, and each trophic control type, the number of models with at least one positive response was counted to give a frequency of occurrence of ASSs. The identity of the disturbance was not considered in this analysis, so if one or all four disturbance scenarios caused a positive ASS response in a model, it was treated as a single positive response. 
Table 1. Ecosim vulnerability settings set to describe the impact of an increase in the biomass of a predator on the predation mortality of its prey (Christensen et al. 2008) under each of four trophic control assumptions. For each trophic control scenario, the functional groups not specifically named were assigned a default vulnerability of 2.0. Vulnerability combinations were applied consistently to all 40 models across the four modeled eras. See Appendix 1 (Table A1.1) for a list of the functional groups described in this table. TD indicates top-down; TD-BU, top-down/bottom-up; BU, bottom-up; WW, wasp-waist.

\begin{tabular}{llll}
\hline \hline & & \multicolumn{2}{c}{ Vulnerability value } \\
\hline Trophic control & 1.0 & 2.0 & 3.0 \\
TD & & Default & WALL3, YLPR3, DCCO \\
TD-BU & Litt. Zoopl., Pel. Zoopl. & Default & WALL3, YLPR3, DCCO \\
BU & Litt. Zoopl., Pel. Zoopl. & Default & \\
WW & Chiro.\&Dip., Amphi., Molluscs\&Gasto., & Default & YLPR1, YLPR2, Sticklebacks, Small Fish \\
& Inverts., Litt. Zoopl., Pelagic Zoopl. & & \\
\hline
\end{tabular}

Fig. 1. Possible Ecosim responses to perturbations modeled as an increase in the fishing effort of a single functional group between years 15 and 20, followed by a return to baseline. Possible model responses were (A) global stability: model groups smoothly returned to the baseline following a perturbation; (B) cycling: model dynamics are cyclic around baseline conditions; and (C) alternate stable states: system attains a different stable equilibrium state. Each line represents the relative biomass of a functional group in a generic model.
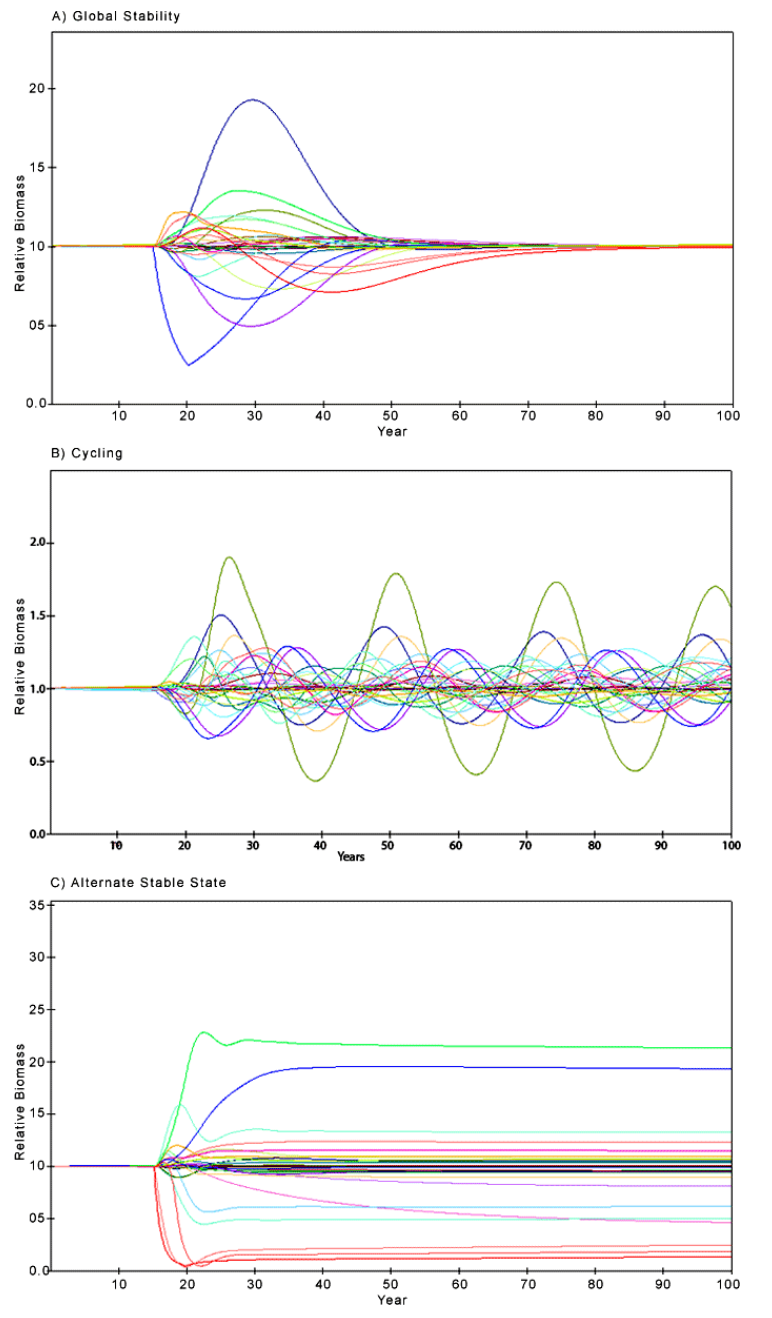

\section{ASS triggers: size and identity}

Models exhibiting ASSs in the baseline assessment of a 10X effort increase for walleye or cormorants, or a $10 \mathrm{X}$ or $100 \mathrm{X}$ increase for perch, were further tested to determine the smallest biomass disturbance resulting from a change in fishing effort required to trigger a transition. On the set of models testing positive for ASSs, we ran an additional 90 scenarios that focused on decreasing fishing effort by $2 \mathrm{X}, 5 \mathrm{X}$, or 10X. Model scenarios are summarized in Table 2, objective 2. Disturbances smaller than 10X were not tested on perch because even at a $10 \mathrm{X}$ increase in fishing effort there was generally no model response in perch biomass, likely because of the high productivity and large biomass of perch relative to walleye or other fish species. Sequential $5 \mathrm{X}$ walleye $/ 5 \mathrm{X}$ cormorant and $5 \mathrm{X}$ cormorant $/ 5 \mathrm{X}$ walleye disturbances were included to test how the order of a change in fishing effort influenced the ability to shift a system between alternate attractors. In the initial assessment of ASSs, both top-down and top-down/bottom-up control scenarios were equally likely to trigger a positive response. All subsequent analyses assumed topdown/bottom-up control because McQueen et al. (1986) concluded that lakes were generally structured by top-down/ bottom-up control.

For models that did not exhibit ASSs in the baseline assessment, additional scenarios were run to determine if a stronger disturbance to fishing effort or a major stocking event was required to trigger a switch between states. We ran an additional 100 scenarios representing increased fishing effort and biomass additions through stocking (Table 2, objective 2). Stocking was modeled through a biomass multiplier on small walleye; the biomass multiplier reflects probable biomass additions to naturally existing walleye fry applied annually to the simulated biomass value in Ecosim. Hatchery stocking was included as a disturbance in this model to shock the walleye biomass in a meaningful way because the adult walleye biomass was too low to initiate an ecosystem response to increased fishing effort. A multiplier of $3000 \mathrm{X}$ was chosen based on the relationship between the modeled biomass of small walleye and the estimated biomass of walleye stocked as fry at Lac la Biche.

For each scenario the intensity of the model response was coded based on the largest positive or negative change in the relative biomass of the functional groups at year 100 of the model run. In all cases, multiple functional groups responded similarly by increasing or decreasing before reaching an asymptotic biomass. 
Table 2. Overview of the number of model scenarios run for each research objective. Year refers to the era of models on which the scenarios were run (All, 1800, 1900, 1965, 2005). TD-BU describes the top-down/bottom-up trophic control assumption (All, topdown, top-down/bottom-up, bottom-up, wasp-waist). Table values report the number of models on which a perturbation scenario was assessed for each for each research question. Perturbation intensity, e.g., 2X, 5X, 10X, describes the magnitude of the fishing effort relative to the Ecopath baseline or stocking increase applied to each group (walleye [Sander vitreus], Double-crested Cormorant [Phalacrocorax auritus], yellow perch [Perca flavescens]) or combination of groups (dual: WALL [walleye]/DCCO [cormorant]). The Dual disturbances tested the model response to an ordered perturbation to walleye then to cormorants, and the reverse, in the same model run.

\begin{tabular}{|c|c|c|c|c|c|c|c|c|c|c|c|c|c|c|c|c|c|c|c|c|}
\hline \multirow[b]{2}{*}{$\begin{array}{l}\text { Objec- } \\
\text { tive }\end{array}$} & \multirow[b]{2}{*}{ Year } & \multirow[b]{2}{*}{$\begin{array}{l}\text { Trophic } \\
\text { Control }\end{array}$} & \multicolumn{6}{|c|}{ Walleye } & \multicolumn{5}{|c|}{ Cormorant } & \multicolumn{4}{|c|}{ Yellow Perch } & \multicolumn{2}{|c|}{ Dual } & \multirow{2}{*}{$\begin{array}{c}\text { Total Runs } \\
\mathrm{N}\end{array}$} \\
\hline & & & $2 \mathrm{X}$ & $5 \mathrm{X}$ & $\begin{array}{l}1- \\
0 \mathrm{X}\end{array}$ & $\begin{array}{c}5- \\
0 \mathrm{X}\end{array}$ & $\begin{array}{l}10- \\
0 X\end{array}$ & $\begin{array}{c}3000 X \\
\text { Stock- } \\
\text { ing }\end{array}$ & $2 X$ & $5 \mathrm{X}$ & $\begin{array}{l}1- \\
0 \mathrm{X}\end{array}$ & $\begin{array}{c}5- \\
0 \mathrm{X}\end{array}$ & $\begin{array}{l}10- \\
0 X\end{array}$ & $\begin{array}{l}1- \\
0 \mathrm{X}\end{array}$ & $\begin{array}{l}10- \\
0 X\end{array}$ & $\begin{array}{l}50- \\
0 X\end{array}$ & $1000 \mathrm{X}$ & $\begin{array}{c}\mathrm{X} \\
\text { WALL } \\
5 \mathrm{X} \\
\mathrm{DCCO} \\
\end{array}$ & $\begin{array}{c}5 \mathrm{X} \\
\text { DCCO } \\
5 \mathrm{X} \\
\text { WALL } \\
\end{array}$ & \\
\hline 1 & $\overline{\text { All }}$ & All & & & $\begin{array}{l}1- \\
60\end{array}$ & & & & & & $\begin{array}{l}1- \\
60\end{array}$ & & & $\begin{array}{l}1- \\
60\end{array}$ & 160 & & & & & 640 \\
\hline 2 & $\begin{array}{c}1800 \\
1900 \\
1965 \\
2005\end{array}$ & $\begin{array}{l}\text { TD-BU } \\
\text { TD-BU }\end{array}$ & 15 & 15 & & & & 20 & 15 & 15 & & 20 & 20 & & & 20 & 20 & 15 & 15 & $\begin{array}{l}90 \\
100\end{array}$ \\
\hline 3 & $\begin{array}{l}2005 \\
\text { Alt. } 1\end{array}$ & $\begin{array}{l}\text { TD-BU } \\
\text { TD-BU }\end{array}$ & 1 & 1 & 1 & 1 & 1 & $\begin{array}{c}12 \\
1\end{array}$ & 1 & 1 & 1 & $\begin{array}{c}12 \\
1\end{array}$ & $\begin{array}{c}12 \\
1\end{array}$ & & & & & 1 & 1 & $\begin{array}{l}36 \\
13\end{array}$ \\
\hline & $\begin{array}{l}\text { Alt. } \\
2,3\end{array}$ & TD-BU & 2 & 2 & 2 & 2 & 2 & & 2 & 2 & 2 & 2 & 2 & & & & & 2 & 2 & 24 \\
\hline & Alt. 4 & TD-BU & 1 & 1 & 1 & 1 & 1 & 1 & 1 & 1 & 1 & 1 & 1 & & & & & 1 & 1 & 13 \\
\hline
\end{tabular}

Model responses were coded as $0=$ no ASS response $(<0.1 \mathrm{X})$; $1=$ weak response $(0.2 \mathrm{X}$ to $0.5 \mathrm{X}) ; 2=$ moderate response $(0.6 \mathrm{X}$ to $2.0 \mathrm{X})$; and $3=$ strong response $(>2.0 \mathrm{X})$. An index of the reaction intensity (IRI) was calculated by multiplying the response code (1 to 3 ) and the frequency of occurrence of each response code for a model era and perturbation type.

\section{Restoration potential for the walleye-dominated equilibrium}

The efficacy of walleye stocking and cormorant control as management tools for restoration was assessed using the 2005 models $(n=12)$ and a set of alternate models that incorporated walleye stocking both directly and indirectly in a variety of ways. The alternate models are described as follows:

1. Modification of a 2005 model to include stocked walleye as a separate multistanza group in the balanced model. All parameters were held constant except the biomass values for the wild walleye group. The walleye stocking disturbance was applied to the stocked walleye group as a $3000 \mathrm{X}$ biomass multiplier on walleye fry.

2. Modification of a 2005 model to increase the Ecopath base walleye biomass to 1900 levels $\left(\sim 2.5 \mathrm{t} / \mathrm{km}^{2}\right)$ to see if the system was capable of supporting a larger walleye population with no changes to other functional group parameters. In addition to the increased biomass for WALL3, the $\mathrm{Q} / \mathrm{B}$ was decreased (WALL3 $=2.0$ /year) and WALL3 diet was shifted from CISC2, YLPR3, Sticklebacks, and Small Fish to YLPR1 and YLPR2. For definition of model elements, see Appendix 1, Table A1.1.

3. Modification of an Ecopath base model for 2005 to make both walleye and cormorant biomasses equivalent to a $1: 1$ prey consumption ratio. To achieve this ratio the biomass for WALL3 was increased $\left(2.0 \mathrm{t} / \mathrm{km}^{2}\right), \mathrm{P} / \mathrm{B}$ was decreased (0.25/year), and Q/B was decreased (1.77/year). Cormorant biomass was decreased to $0.068 \mathrm{t} / \mathrm{km}^{2}$, and diet composition for WALL3 was shifted from CISC1, CISC2, YLPR3, Sticklebacks, and Small Fish to YLPR1 and YLPR2.

4. Creation of a new Ecopath model (2011) using data from Lac la Biche representing conditions in 2011 in which walleye stocked between 2006 and 2011 were incorporated directly into the population of wild walleye. Parameters for most groups differed from the 2005 models, although they remain within the ranges used in parameterizing other models.

Scenarios tested on each alternate model are summarized in Table 2, objective 3 .

Relationship between walleye, perch, and cormorants in ASSs The resilience of an equilibrium state depends on reinforcement by stabilizing feedbacks and the extent to which the abiotic and biotic components have been changed (Briske et al. 2008). We assessed the change over time in the relative influence of walleye, perch, and cormorants in the system in terms of their direct foraging impact. For each set of models representing a different time period, i.e., 1800, 1900, 1965, and 2005, with and without ASSs, we averaged the biomass and Q/B values for the three walleye groups, three perch groups, and one cormorant group. We multiplied the average biomass $\left(\mathrm{t} / \mathrm{km}^{2}\right)$ for each group by its average $\mathrm{Q} / \mathrm{B}$ per year to calculate the total consumption $\left(\mathrm{t} \cdot \mathrm{km}^{-2}\right.$. $\left.\mathrm{yr}^{-1}\right)$ by group. The three walleye estimates were summed to get a single consumption estimate for walleye and likewise for perch. Ratios of foraging intensity were calculated relative to cormorant consumption to elucidate changes in the ratios between systems with and without ASSs. 


\section{Recent ecosystem trends in response to predator manipulation} Empirical data describing the ecosystem response to restoration efforts were assessed to determine if early trends in the perch, walleye, or cormorant populations resemble those of the simulation model outputs. Relative trends in perch and walleye population size were assessed in terms of catch-per-unit-effort (CPUE; fish $\cdot 100 \mathrm{~m}^{-2} \cdot 24 \mathrm{~h}^{-1}$ ) calculated from index netting data collected by Alberta Environment and Sustainable Resource Development from 2005 to 2012. (Data were provided by the Fish \& Wildlife Management Information System, Alberta Sustainable Resource Development, Edmonton, Alberta, Canada.) CPUE (fish $\cdot 100 \mathrm{~m}^{-2} \cdot 24 \mathrm{~h}^{-1}$ ) data were bootstrapped 10,000 times, and the median and $95 \%$ confidence intervals were plotted. Trends in cormorant abundance were assessed from annual nest count data over the same period of 2005 to 2012 .

\section{RESULTS}

\section{Assessment of ASSs}

In total, we found ASSs in $70 \%$ to $80 \%$ of historic models (1800, $1900)$ but in none of the contemporary models $(1965,2005$; Table 3). Assumptions of top-down and top-down/bottom-up control gave the largest number of positive results: $70 \%$ in 1800 and $80 \%$ in 1900 . We also observed alternate state responses under bottomup control in $20 \%$ of the 1800 models and $30 \%$ of the 1900 models. Trophic control assumptions did not influence the occurrence of ASSs in the contemporary models, so further analysis of the nature of ASSs was restricted to the two historical models: 1800 and 1900 .

Table 3. Number of models that exhibited an alternate stable state response to at least one of four perturbations under each of four different trophic control scenarios. TD indicates top-down; TDBU, top-down/bottom-up; BU, bottom-up; WW, wasp-waist.

\begin{tabular}{cccccc}
\hline \hline Year & N & TD & TD-BU & BU & WW \\
\hline 1800 & 10 & 7 & 7 & 2 & 0 \\
1900 & 10 & 8 & 8 & 3 & 0 \\
1965 & 8 & 0 & 0 & 0 & 0 \\
2005 & 12 & 0 & 0 & 0 & 0 \\
\hline
\end{tabular}

\section{ASS triggers: size and identity}

Larger perturbations, i.e., 10X walleye and cormorant and 100X perch, were equally as likely to trigger a positive ASS response in 1800 as in 1900 (Table 4). In 1800, there was a large jump in positive responses between $2 \mathrm{X}$ and $5 \mathrm{X}$ perturbations for walleye $(100 \%)$ and cormorants $(75 \%)$, and between $10 \mathrm{X}$ and $100 \mathrm{X}$ for perch $(250 \%)$. Between 1800 and 1900, the number of scenarios exhibiting an ASS response increased most, relative to the 1800 response frequency, for disturbances targeting walleye and for the smallest perturbation ( $2 \mathrm{X}, 133 \%$; $\mathrm{X}, 33 \%$; 10X, 14\% increase). We observed a similar trend with increases in cormorant and perch fishing effort. In 1800, a walleye disturbance preceding a cormorant disturbance was $80 \%$ more likely to trigger a switch between equilibrium states, whereas in 1900, disturbing cormorants first caused a larger number of switches (75\%).

The magnitude or intensity of a positive ASS response, measured as the deviation from baseline, following a disturbance increased between model years, especially for perturbations in walleye fishing effort (Table 4). For a given year, response intensity increased with perturbation size across all disturbance types, especially between a $2 \mathrm{X}$ and $5 \mathrm{X}$ fishing effort increase for walleye $(120 \%)$ and cormorants $(170 \%)$. In general, small perturbations, i.e., $2 X$, caused more intense ASS responses in 1900 than in 1800 regardless of the nature of the trigger. Disturbances targeting walleye caused the most intense ASSs reactions in general, but the largest overall impact was for a $10 \mathrm{X}$ increase in cormorant effort. Disturbances to perch triggered less intense ASS responses than disturbances to either walleye or cormorants.

None of the contemporary models tested positive for ASSs even when the perturbation size was dramatically increased. Lowamplitude cycling around baseline was evident in $25 \%$ of models under top-down, mixed, and wasp-waist trophic control, and $17 \%$ of bottom-up models. Cycling was generally triggered by perch perturbations, although cormorant perturbations $10 \mathrm{X}$ or larger triggered cycling in mixed control models. In all other cases, the models exhibited a single equilibrium dominated by cormorants.

\section{Restoration potential for walleye-dominated equilibrium}

Among the 86 model scenarios representing the current ecosystem (2005, 15 models; 2011, 1 model), there were 2 ASS responses. In alternate model 4 , the $50 \mathrm{X}$ and $100 \mathrm{X}$ cormorant perturbations eliminated cormorants from the system, resulting in an apparent ASS with persistently high walleye biomass.

Cycling was not observed in any of the four alternate models using conservative vulnerability values. Tests using higher vulnerabilities $(5.0,10.0)$ triggered cycling in alternate models 2 and 3 under all perturbations, and in alternate model 1 when cormorant effort was increased.

The 2005 and 2011 contemporary models responded to the addition of stocked walleye with a spike in the relative biomass of each walleye age stanza. For adult walleye, the spike in relative biomass ranged from $2 \mathrm{X}$ to $300 \mathrm{X}$ and was sustained for 15 to 20 years before returning to the low baseline biomass. Large spikes in walleye biomass had little perceptible impact on other modeled groups.

Relationship between walleye, perch, and cormorants in ASSs In general, we found that total consumption of prey by walleye decreased with time, whereas the total consumption by cormorants increased in all years except 1965 (Table 5). Relative to total consumption by cormorants, consumption by walleye was up to four times higher in the historic models but one to two orders of magnitude lower in the contemporary models. Total consumption by perch generally increased between model years, with the exception of "no ASS" models for 1800, although relative consumption was highest in 1965 when both cormorant and walleye total consumption was low.

\section{Recent ecosystem trends in response to predator manipulation}

Field data collected between 2005 and 2012 indicate the nesting cormorant population declined $82 \%$ in response to management efforts (Fig. 2). During the same period stocking increased the walleye CPUE from 0.09 walleye $\cdot 100 \mathrm{~m}^{-2} \cdot 24 \mathrm{~h}^{-1}$ to between 16 and 18 walleye $\cdot 100 \mathrm{~m}^{-2} \cdot 24 \mathrm{~h}^{-1}$. Perch CPUE did not show a consistent trend, though CPUE in the last year of survey (2012) was more than $500 \%$ larger than the 2005 level. Perch catch rate peaked in 2009 (297 perch $\left.\cdot 100 \mathrm{~m}^{-2} \cdot 24 \mathrm{~h}^{-1}\right)$, fluctuating in recent years between 99 perch $\cdot 100 \mathrm{~m}^{-2} \cdot 24 \mathrm{~h}^{-1}$ in 2010 and 188 perch $\cdot 100 \mathrm{~m}^{-2} \cdot 24$ $\mathrm{h}^{-1}$ in 2011 . 
Table 4. Model responses to different combinations of perturbation type and intensity. "\# ASS" refers to the number of models that exhibited an alternate stable state (ASS) reaction in response to each type and intensity of perturbation. The index of reaction intensity (IRI) refers to the size of the system response to each type and intensity of perturbation, measured as the change in relative biomass of the model groups that were most impacted. The IRI was calculated as the magnitude of the response $(0=$ no response to $3=$ strong response) multiplied by the frequency of each type of response. The "Dual" disturbances tested the model response to an ordered perturbation to walleye then cormorants (and the reverse) in the same model run. DCCO indicates Double-crested Cormorant (Phalacrocorax auritus); WALL, walleye (Sander vitreus); YLPR, yellow perch (Perca flavescens).

\begin{tabular}{|c|c|c|c|c|c|c|c|c|c|c|c|c|}
\hline \multirow[b]{2}{*}{ Reaction } & \multirow[b]{2}{*}{ Year } & \multirow[b]{2}{*}{$\mathrm{N}$} & \multicolumn{3}{|c|}{ Walleye } & \multicolumn{3}{|c|}{ Cormorant } & \multicolumn{2}{|c|}{ Yellow Perch } & \multicolumn{2}{|c|}{ Dual } \\
\hline & & & $2 X$ & $5 \mathrm{X}$ & $10 \mathrm{X}$ & $2 \mathrm{X}$ & $5 X$ & $10 \mathrm{X}$ & $10 X$ & $100 \mathrm{X}$ & $\begin{array}{c}5 \mathrm{X} \\
\text { WALL } \\
5 \mathrm{X} \\
\text { DCCO }\end{array}$ & $\begin{array}{l}\text { 5X DCCO 5X } \\
\text { WALL }\end{array}$ \\
\hline \multirow[t]{2}{*}{ \# ASS } & 1800 & 10 & 3 & 6 & 7 & 4 & 7 & 7 & 2 & 7 & 5 & 1 \\
\hline & 1900 & 10 & 7 & 8 & 8 & 5 & 7 & 7 & 3 & 7 & 1 & 4 \\
\hline \multirow[t]{2}{*}{ IRI } & 1800 & 10 & 5 & 11 & 15 & 6 & 16 & 18 & 4 & 12 & 9 & 2 \\
\hline & 1900 & 10 & 13 & 18 & 18 & 9 & 15 & 19 & 6 & 14 & 1 & 8 \\
\hline
\end{tabular}

Table 5. Average total consumption $\left(\mathrm{t} \cdot \mathrm{km}^{-2 /} \cdot \mathrm{yr}^{-1 /}\right)$ of Doublecrested Cormorants (DCCO; Phalacrocorax auritus), yellow perch (YLPR; Perca flavescens), and walleye (WALL; Sander vitreus) by year for models exhibiting alternate stable states (ASSs) and models that did not (no ASS). The ratio represents total yellow perch and walleye consumption relative to one unit of cormorant consumption.

\begin{tabular}{lcccccc}
\hline \hline & \multicolumn{5}{c}{$\begin{array}{c}\text { Total Consumption } \\
\left(\mathrm{t} \cdot \mathrm{km}^{-2} \cdot \mathrm{yr}^{-1}\right)\end{array}$} \\
\cline { 4 - 6 } Reaction & Year & $\mathrm{N}$ & DCCO & YLPR & WALL & Ratio \\
\hline ASS & 1800 & 7 & 1.5 & 25.4 & 6.1 & $1: 17: 4$ \\
& 1900 & 8 & 4.4 & 30.9 & 5.1 & $1: 7: 1$ \\
\multirow{4}{*}{ No ASS } & 1800 & 3 & 1.5 & 83.6 & 8.8 & $1: 56: 6$ \\
& 1900 & 2 & 2.9 & 51.7 & 8.8 & $1: 18: 3$ \\
& 1965 & 8 & 0.5 & 53.6 & 0.07 & $1: 107: 0.1$ \\
& 2005 & 12 & 22.4 & 159.8 & 0.2 & $1: 7: 0.009$ \\
\hline
\end{tabular}

\section{DISCUSSION}

By using a series of ecosystem models over a period of intense ecosystem change, we found that ASSs, defined by walleyedominated and cormorant-dominated equilibria, existed in historical models, whereas contemporary models had a single attractor. We also found that in 1900, ASSs were triggered by smaller perturbations than in 1800 and that the intensity of the modeled response was stronger in 1900. Disturbances impacting walleye and cormorant populations were more likely to trigger a positive reaction than disturbances to perch. These results provide important theoretical and practical insights for restoration of Lac la Biche and other large lake ecosystems.

Altered trophic interactions resulting in ASSs have been documented across a range of habitats. In riparian areas, regenerating saplings are consumed by foraging deer, thus hindering the recovery of woody species (Opperman and Merenlender 2000). In semiarid grasslands, vegetation shifts have
Fig. 2. Comparison of walleye (Sander vitreus) and yellow perch (Perca flavescens) catch-per-unit-effort (CPUE; fish·100 $\left.\mathrm{m}^{-2} \cdot 24 \mathrm{~h}^{-1}\right)$ from fall index netting using multimesh gill nets (data were provided by the Fish \& Wildlife Management Information System, Alberta Sustainable Resource Development, Edmonton, Alberta, Canada) and Doublecrested Cormorant (Phalacrocorax auritus) nest counts for each year of the Lac la Biche fishery restoration program between 2005 and 2012. Error bars show 95\% confidence intervals on the median of the CPUE data bootstrapped 10,000 times.

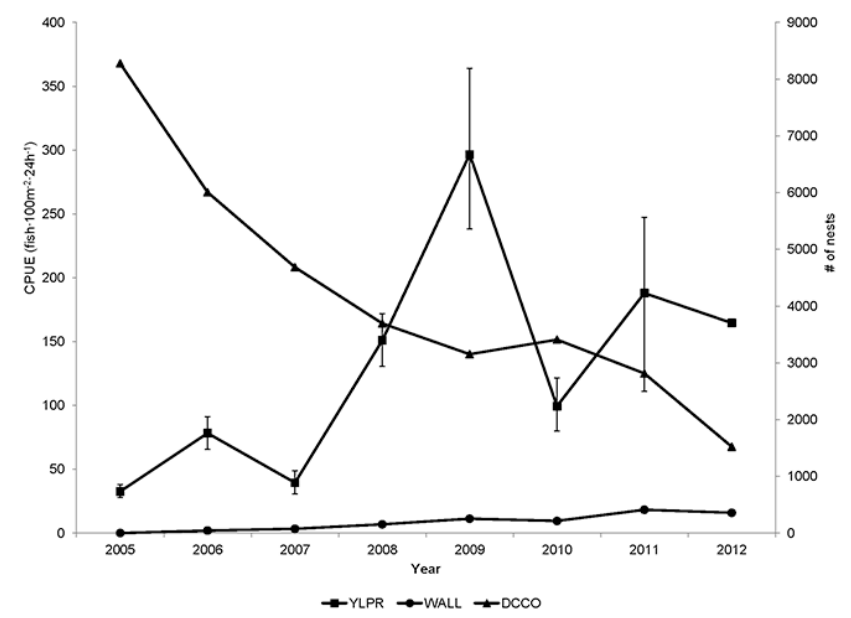

occurred following periods of overgrazing by domestic animals (Van Auken 2000). Vegetated marshes have been converted to mudflats and open water following overgrazing of soil roots and rhizomes by growing populations of Lesser Snow Geese (Chen caerulescens caerulescens; Miller et al. 1996). And in both marine systems (Daskalov et al. 2007, Casini et al. 2009) and freshwater systems (Persson et al. 2007, Carpenter et al. 2011, Ellis et al. 2011), trophic cascades have resulted from fisheries overharvest and the introduction of piscivorous predators. Recently, attention 
has turned to the role of piscivorous birds as top predators in aquatic ecosystems (Steinmetz et al. 2003), most notably cormorants.

Cormorants have been linked to declines in fish populations (Fielder 2010, Dorr et al. 2012), delayed fish population recovery (Barks et al. 2010), and reduced fishery potential (Rudstam et al. 2004). To this point, most research on cormorant-fishery conflicts has focused on single-species assessments of predation impacts on fish stocks and stock recovery after cormorant management (but see Mills et al. 2003, Miehls et al. 2009). However, equivocal assessments of cormorant impacts in Europe led Davies et al. (2003) to conclude that a holistic approach is necessary in studies of the relationship between fish-eating birds and fisheries, largely because of the complexity of systems. Our study is the first to link cormorant increases and fishery recovery concerns with ASS dynamics in large lake ecosystems and, along with the study by Feng et al. (2006), is one of the first to find ASSs in aquatic ecosystems using Ecopath with Ecosim software.

Most studies of ASS dynamics have occurred over time periods that allow observation or measurement of conditions leading to both possible states (for examples, see Chase 2003, Konar and Estes 2003). Restoration challenges at Lac la Biche over the last 20 years could not be explained by available data or observations from the recent past, leading us to examine changes that occurred over a period too far in the past to have been observed, measured, and documented. By using Ecopath with Ecosim software to create feasible representations of the ecosystem during different eras, we were able to test hypotheses about the system's likely response to changes in fishing effort and fish stocking, and provide insight on the existence and possible loss of ASSs through incremental changes in ecosystem conditions. Without the historical models, there would be only theoretical support for the existence of ASSs at Lac la Biche. These results help explain the current restoration challenges and can help guide future management actions.

Using models to illustrate ASSs has been widely criticized (Dudgeon et al. 2010), but also promoted as an important tool for increasing our understanding about sensitive species and systems at reduced financial cost and low risk (Hobbs and Suding 2009). Ecopath with Ecosim is a useful and accessible tool for organizing information and assumptions into energetically plausible representations of an ecosystem, but like all models, it has limitations arising from a general lack of data and an inability to accurately reflect some system dynamics.

Models created to simulate large lake ecosystems often lack appropriate empirical data for parameterization. Thus, modelers must rely on qualitative information, available history, local knowledge, ecological principles and theory, and limited data to create an informed representation of the whole system. Even given the best available data, model balancing requires modifying input parameters, which leads to multiple descriptions of the same food web. The balancing process can be done subjectively by the modeler, as was the case in this study, or objectively by the software (Langseth 2012). Although modeler bias can be a criticism of the subjective approach, Essington (2007) found both approaches led to similar variation in model input parameters, lending validity to models that were balanced based on the modelers' knowledge and logic.
Systematic model validation was not possible for representations of 1800,1900 , or 1965 conditions because no information existed against which model performance could be assessed. Despite having several years of empirical fisheries data describing population changes since 2005 , we cannot judge the validity of the model results solely by comparing simulated outputs with the available data. Ecosim was not parameterized to provide the best fit to the empirical data; rather, the purpose was to consistently assess ASSs between eras based solely on differences in the Ecopath base model parameterization and assumptions of trophic control. Changing Ecosim parameters can significantly affect model outcomes (Langseth 2012), which would have made it difficult to compare results between eras. Furthermore, the empirical data were collected during a period of active, direct disturbance to both cormorants and walleye, so the actual ecosystem was in a period of dynamic instability during this time. Ecosim results based on the 2005 Ecopath models cannot be expected to mimic these dynamics over such a short time frame and in the first 5 to 10 years of a simulation before the model has stabilized. Although a visual comparison of the general trends in cormorants, walleye, and perch population sizes suggests consistency with modeling results, using available data to validate Ecosim outputs in a more robust way is inappropriate given the overall research approach.

All analyses conducted after the initial test for ASSs assumed topdown/bottom-up system control because McQueen (1986) concluded that lakes were generally structured in this way. It is important to note, however, that if a strong top-down control had been modeled instead, the size of disturbance triggering an ASS could have been lower than that reported in this study. If strong bottom-up control was chosen for subsequent analysis, the disturbance limit for triggering an ASS could have been much higher.

We relied on the consistency of the perturbation responses across models in each era to improve confidence in the results of this research. Using multiple model iterations for each era captured the variability in possible ecosystem conditions, and by applying the same treatment to each set of models and reporting the frequency of ASSs, we increased confidence in the likelihood of the result. However, weaknesses were identified that could have impacted the outcome of some scenarios. A frequent problem during model balancing was overconsumption of intermediate trophic-level species beyond what was available, causing ecotrophic efficiencies to exceed their maximum value. This issue has been identified by other Ecopath users, and could arise either from the inconsistent spatial or temporal representation of functional groups, or a flaw in the modeling framework (Stewart and Sprules 2011, Langseth 2012). Perceived overconsumption could make it difficult to accurately identify ASSs caused by either a trophic cascade or a cultivation/depensation effect because both are dependent on the relationships between top predators, i.e., cormorants and walleye, and their primary prey, i.e., perch. Although this could impact the conclusions of this study, the consistency of the results should alleviate some concern. The difficulty in incorporating stocked fish biomass is another potential weakness of the modeling software that could influence our understanding of the practical potential for fisheries restoration through stocking. However, the failure to produce a walleye-dominated state in any of the base 2005 models or the 
four alternate models supports the theoretical conclusion that the potential for a walleye-dominated ecosystem resembling historical conditions has been lost.

For an Ecopath model to exhibit ASS dynamics when forced with a perturbation in Ecosim, the model has to exist on the verge of stability; a small change in one parameter value leads to one stability domain, whereas a change in the opposite direction or to a different parameter leads to an ASS. The domain of parameter combinations that will result in multiple equilibria is very narrow. As a result, the "appropriate" combination of parameters is rarely found; and when it is, it is generally achieved through a process of targeted trial and error, causing some to suggest that model outputs represent only what the models were specified to do. The 40 models used in this study were parameterized using the best available data for each era, and the occurrence of ASSs in the historical models represents an emergent property rather than a created condition. Given the difficulty with which ASSs are actually produced, that we observed a positive response in $75 \%$ of the historical models representing a range of feasible parameter combinations for Lac la Biche supports our conclusion that ASSs are a property of the historical ecosystem.

Shifts between alternate attractors result from a combination of the magnitude of a perturbation and the resilience of the ecosystem (Folke et al. 2004). When resilience is reduced by human actions, it becomes increasingly likely that a smaller perturbation will trigger an ASS (Folke et al. 2004). Evidence from model scenarios of 1800 and 1900 suggest a decline in system resilience, which is supported by historical accounts from the area (McGregor 2013b). For example, overharvest during European settlement of Lac la Biche caused the reported decline of lake whitefish by the late 1870s (McCullough and Maccagno 1991). Reports of variability in the availability of lake whitefish (Champagne 1992) and the frequency of drought conditions (Dominion of Canada 1887, Champagne 1992) and stochastic weather events (Dominion of Canada 1888, McCullough and Maccagno 1991) were increasingly common toward the end of the century. In addition to lake whitefish harvest, historical harvest of northern pike, walleye, suckers (Catostomus spp.), and burbot (Lota lota) also occurred (Tyrell 1916, as cited in McCullough and Maccagno 1991) with potential impacts on ecosystem resilience.

The failure of walleye stocking, cormorant control, or increased perch fishing to result in ASSs in any of the contemporary models may be explained in several ways. Apart from the previously discussed issues with model parameterization and the incorporation of stocked walleye, the absence of ASSs could have occurred because (1) perturbations were not large enough to trigger a positive response because of high system resilience, (2) ASSs existed but required different "triggers" that we did not test, or (3) the current system has a single attractor. If any of the first options is true, then a combined research and management approach should focus on fine-tuning parameter estimates, finding a better way to incorporate stocked fish, and identifying appropriate triggers to improve understanding of the restoration trajectory (Hobbs and Suding 2009). If, however, one of the historical attractors has been lost because of changing ecosystem conditions (Beisner et al. 2003), current management will not be able to restore the walleye-dominated state of historical times because the potential for that state does not exist under current conditions.

Identifying the success of the restoration program at Lac la Biche depends on the temporal scale of assessment. If walleye stocking and cormorant control are judged annually or over the shortterm, then from the perspective of an angler or a fisheries manager the walleye population can be "restored" in virtually all scenarios. The increasing trend in walleye CPUE over seven years of index netting supports the results of contemporary model scenarios suggesting that walleye recovery is indeed under way. However, what remains to be seen is whether the model prediction, i.e., that the adult walleye biomass originating from stocking will only be sustained for 15 to 20 years before returning to the baseline Ecopath biomass, does indeed occur. Thus, from a long-term perspective, restoration of the walleye-dominated state will not occur given current management actions because the walleyedominated state does not exist. The loss of an attractor could have occurred if critical parameters or environmental conditions changed and altered the stability landscape of the system (Beisner et al. 2003, Petraitis and Dudgeon 2004, Scheffer 2009). At Lac la Biche, changes to ecosystem conditions through the 20th century were numerous. Fish populations were heavily harvested, walleye were extirpated, major fish kills occurred in 1946 and 1965 , the watershed was cleared for agriculture, treated sewage discharge into the lake began, and settlement around the lake increased (Champagne 1992, Schindler et al. 2008). Any one of these activities could have altered important ecosystem parameters, thereby eroding system resilience (Folke et al. 2004) and changing the system's potential for ASSs. Irreversible regime shifts resulting from a change in environmental conditions and the loss of an attractor (stability state) have also been documented in cloud forests when tree clearing permanently alters the moisture regime (Wilson and Agnew 1992), or following periods of overhunting that remove or seriously alter wildlife populations (Zimov et al. 1995).

Petraitis and Dudgeon (2004:362) suggest that an alternate state is stable when "at least one of the species in the alternative community ... become[s] common enough in biomass, individual size, and/or density ... to establish the positive feedbacks needed to maintain the assemblage." Evaluation of the ratios of total consumption for cormorants, perch, and walleye supports the hypothesis that the alternate attractors are stabilized through the differential predator-prey interactions of cormorants and walleye with their main prey source, perch. In 2005, the cormorant biomass was large enough that by dominating walleye and perch in terms of total consumption, we expect cormorants were able to establish a strong feedback within the population of a key prey source, i.e., perch. In contrast, in the historical models walleye were more likely than cormorants to influence the structure of the prey community through size-selective foraging. The combined selection pressure from foraging of walleye and large perch in the historical models is much less than the impact of cormorant consumption in models of 2005, which might explain the lower resilience of the historical models. Using total consumption as an indicator for trophic impact does not account for indirect effects of species within the system. However, results from Ecopath's mixed trophic impacts assessment suggested only weak indirect effects of cormorants, walleye, and perch (A. 
McGregor, unpublished data). If similar ratios are found in other systems and across functionally similar species, the calculation and comparison of consumption ratios could inform proactive management of aquatic systems by helping to identify ASS conditions or guide restoration.

\section{CONCLUSIONS}

Given the results of this study, we would suggest that restoration of the historical walleye-dominated equilibrium is not possible, but that the current management strategy, including continued intervention in the form of walleye stocking and cormorant control, provides opportunity for a recovery of the walleye population under a different set of ecosystem conditions than historically existed. Continued monitoring of system dynamics is important for the adaptive management cycle, improved modeling, and to provide indicators of long-term system dynamics (Hobbs and Suding 2009). Although the time frame for assessing the conclusions of this study is long, continuity of the research is critically important for improving the modeling process and building the link between theoretical and empirical knowledge of ASSs.

Responses to this article can be read online at: http://www.ecologyandsociety.org/issues/responses. $\mathrm{php} / 7350$

\begin{abstract}
Acknowledgments:
We are grateful to the staff of Alberta Sustainable Resource Development for their commitment to the field component of the program. We thank M.G. Sullivan for his review of this manuscript. Funding for this study was provided by Alberta Sustainable Resource Development, the Natural Sciences and Engineering Council, the Alberta Conservation Association, and the Canadian Circumpolar Institute.
\end{abstract}

\section{LITERATURE CITED}

Araujo, J. N., S. Mackinson, R. J. Stanford, D. W. Sims, A. J. Southward, S. J. Hawkins, J. R. Ellis, and P. J. B. Hart. 2006. Modelling food web interactions, variation in plankton production, and fisheries in the western English Channel ecosystem. Marine Ecology Progress Series 309:175-187. http:// dx.doi.org/10.3354/meps309175

Barks, P. M., J. L. Doucette, and C. M. Somers. 2010. Lack of angling-sized yellow perch in a Canadian boreal lake: potential influences of growth rate, diet, and predation by double-crested cormorants. Transactions of the American Fisheries Society 139:1029-1040. http://dx.doi.org/10.1577/T09-174.1

Beisner, B. E., D. T. Haydon, and K. Cuddington. 2003. Alternative stable states in ecology. Frontiers in Ecology and the Environment 1(7):376-382. http://dx.doi.org/10.1890/1540-9295 (2003)001[0376:ASSIE]2.0.CO;2

Briske, B. B., B. T. Bestelmeyer, T. K. Stringham, and P. L. Shaver. 2008. Recommendations for development of resilience-based state-and-transition models. Rangeland Ecology \& Management 61:359-367. http://dx.doi.org/10.2111/07-051.1
Carpenter, S. R., W. A. Brock, J. J. Cole, J. F. Kitchell, and M. L. Pace. 2008. Leading indicators of trophic cascades. Ecology Letters 11:128-138. http://dx.doi.org/10.1111/j.1461-0248.2007.01131. $\underline{\mathrm{X}}$

Carpenter, S. R., J. J. Cole, M. L. Pace, R. Batt, W. A. Brock, T. Cline, J. Colose, J. R. Hodgson, J. F. Kitchell, D. A. Seekall, L. Smith, and B. Weidel. 2011. Early warnings of regime shifts: a whole-ecosystem experiment. Science 332:1079-1082. http://dx. doi.org/10.1126/science. 1203672

Casini, M., J. Hjelm, J.-C. Molinero, J. Lövgren, M. Cardinale, V. Bartolino, A. Belgrano, and G. Kornilovs. 2009. Trophic cascades promote threshold-like shifts in pelagic marine ecosystems. Proceedings of the National Academy of Sciences of the United States of America 106:197-202. http://dx.doi.org/10.1073/ pnas.0806649105

Champagne, J. 1992. Mission Notre-Dame-des-Victoires, Lac la Biche: interpretive matrix and narrative history. Lac la Biche Mission Historical Society and Historic Site Services, Alberta Culture and Multiculturalism, Lac La Biche, Alberta, Canada.

Chase, J. M. 2003. Experimental evidence for alternative stable equilibria in a benthic pond food web. Ecology Letters 6:733-741. http://dx.doi.org/10.1046/j.1461-0248.2003.00482.x

Christensen, V., C. J. Walters, D. Pauly, and R. Forrest. 2008. Ecopath with Ecosim version 6 user guide. Lenfest Ocean Futures Project, University of British Columbia, Vancouver, British Columbia, Canada. [online] URL: ftp://download.ecopath.org/ Help/Ewe $\% 20$ User $\% 20$ Guide $\% 206 . p d f$

Coll, M., A. Santojanni, I. Palomera, S. Tudela, and E. Arneri. 2006. An ecological model of the Northern and Central Adriatic Sea: analysis of ecosystem structure and fishing impacts. Journal of Marine Systems 67:119-154. http://dx.doi.org/10.1016/j. imarsys.2006.10.002

Connell, J. H., and W. P. Sousa. 1983. On the evidence needed to judge ecological stability or persistence. American Naturalist 121:789-824. http://dx.doi.org/10.1086/284105

Dalton, C. M., D. Ellis, and D. M. Post. 2009. The impact of double-crested cormorant (Phalacrocorax auritus) predation on anadromous alewife (Alosa pseudoharengus) in south-central Connecticut, USA. Canadian Journal of Fisheries and Aquatic Sciences 66:177-186. http://dx.doi.org/10.1139/F08-198

Daskalov, G. M., A. N. Grishin, S. Rodionov, and V. Mihneva. 2007. Trophic cascades triggered by overfishing reveal possible mechanisms of ecosystem regime shifts. Proceedings of the National Academy of Sciences of the United States of America 104:10518-10523. http://dx.doi.org/10.1073/pnas.0701100104

Davies, J. M., T. Holden, M. J. Fetham, B. R. Wilson, J. R. Britton, J. P. Harvey, and I. G. Cowx. 2003. The relationship between cormorant and fish populations at two fisheries in England: an overview. Pages 28-42 in I. G. Cowx, editor. Interactions between fish and birds: implications for management. Blackwell Science, Oxford, UK. http://dx.doi.org/10.1002/9780470995372.ch3

Dominion of Canada. 1887. Annual report of the Department of Indian Affairs for the year ended 31st December, 1886. Ottawa, Ontario, Canada. [online] URL: http://www.bac-lac.gc.ca/eng/ 
discover/aboriginal-heritage/first-nations/indian-affairs-annual-reports/ Pages/item.aspx?IdNumber $=4576 \mathrm{a}$

Dominion of Canada. 1888. Annual report of the Department of Indian Affairs for the year ended 31st December, 1887. Ottawa, Ontario, Canada. [online] URL: http://www.bac-lac.gc.ca/eng/ discover/aboriginal-heritage/first-nations/indian-affairs-annual-reports/ Pages/item.aspx?IdNumber $=5200$

Dorr, B. S., S. L. Hanisch, P. H. Butchko, and D. G. Fielder. 2012. Management of double-crested cormorants to improve sport fisheries in Michigan: three case studies. Human-Wildlife Interactions 3:155-168.

Dudgeon, S. R., R. B. Aronson, J. F. Bruno, and W. F. Precht. 2010. Phase shifts and stable states on coral reefs. Marine Ecology Progress Series 413:201-216. http://dx.doi.org/10.3354/meps08751

Ellis, B. K., J. A. Stanford, D. Goodman, C. P. Stafford, D. L. Gustafson, D. A. Beauchamp, D. W. Chess, J. A. Craft, M. A. Deleray, and B. S. Hansen. 2011. Long-term effects of a trophic cascade in a large lake ecosystem. Proceedings of the National Academy of Sciences of the United States of America 108:1070-1075. http://dx.doi.org/10.1073/pnas.1013006108

Essington, T. E. 2007. Evaluation of the sensitivity of a trophic mass-balance model(Ecopath) to imprecise data inputs. Canadian Journal of Fisheries and Aquatic Sciences 64:628-637. http://dx. doi.org/10.1139/f07-042

Feng, J., H. Wang, D. Huang, and S. Li. 2006. Alternative attractors in marine ecosystems: a comparative analysis of fishing effects. Ecological Modelling 195:377-384. http://dx.doi. org/10.1016/j.ecolmodel.2005.11.033

Fielder, D. G. 2008. Examination of factors contributing to the decline of the yellow perch population and fishery in Les Cheneaux Islands, Lake Huron, with emphasis on the role of double-crested cormorants. Journal of Great Lakes Research 34:506-523. http://dx.doi.org/10.3394/0380-1330(2008)34[506:EOFCTT] 2.0. $\mathrm{CO} ; 2$

Fielder, D. G. 2010. Response of yellow perch in Les Cheneaus Islands, Lake Huron to declining numbers of double-crested cormorants stemming from control activities. Journal of Great Lakes Research 36:207-214. http://dx.doi.org/10.1016/j.jglr.2009.12.015

Folke, C., S. Carpenter, B. Walker, M. Scheffer, T. Elmqvist, L. Gunderson, and C. S. Holling. 2004. Regime shifts, resilience, and biodiversity in ecosystem management. Annual Review of Ecology, Evolution, and Systematics 35:557-581. http://dx.doi. org/10.1146/annurev.ecolsys.35.021103.105711

Hobbs, R., and K. Suding. 2009. Models of ecosystem dynamics as frameworks for restoration ecology. Pages 3-21 in R. Hobbs and K. Suding, editors. New models for ecosystem dynamics. Island Press, Washington, D.C., USA.

Konar, B., and J. A. Estes. 2003. The stability of boundary regions between kelp beds and deforested areas. Ecology 84:174-185. http://dx.doi.org/10.1890/0012-9658(2003)084[0174:TSOBRB]2.0. $\underline{\mathrm{CO} ; 2}$

Langseth, B. J. 2012. An assessment of harvest policies for a multispecies fishery in Lake Huron using a food-web model. Dissertation. Michigan State University, East Lansing, Michigan, USA.
McCullough, E. J., and M. Maccagno. 1991. Lac la Biche and the early fur traders. Boreal Institute for Northern Studies Occasional Publication No. 29. Canadian Circumpolar Institute, Edmonton, Alberta, Canada.

McGregor, A. 2013a. Fish harvest and the replacement of top piscivorous predators in aquatic food webs: implications for restoration and fisheries management. Dissertation. University of Alberta, Edmonton, Alberta, Canada.

McGregor, A. M. 2013b. Of fur and fins: quantifying fur trade era fish harvest to assess changes in contemporary Lake Whitefish (Coregonus clupeaformis) production at Lac La Biche, Alberta. Journal of Ecological Anthropology 16:5-26. http://dx.doi. org/10.5038/2162-4593.16.1.1

McGregor, A. M. 2014. Using Ecopath modelling to describe historical conditions for a large, boreal lake ecosystem prior to European settlement. North American Journal of Fisheries Management 34:16-29. http://dx.doi.org/10.1080/02755947.2013.833559

McQueen, D. J., J. R. Post, and E. L. Mills. 1986. Trophic relationships in freshwater pelagic ecosystems. Canadian Journal of Fisheries and Aquatic Sciences 43:1571-1581. http://dx.doi. org/10.1139/f86-195

Miehls, A. L. J., D. M. Mason, K. A. Frank, A. E. Krause, S. D. Peacor, and W. W. Taylor. 2009. Invasive species impacts on ecosystem structure and function: a comparison of Oneida Lake, New York, USA, before and after zebra mussel invasion. Ecological Modelling 220:3194-3209. http://dx.doi.org/10.1016/j. ecolmodel.2009.07.020

Miller, D. L., F. E. Smeins, and J. W. Webb. 1996. Mid-Texas coastal marsh change (1939-1991) and influenced by lesser snow goose herbivory. Journal of Coastal Research 12:462-476.

Mills, E. L., J. M. Casselman, R. Dermott, J. D. Fitzsimons, G. Gal, K. T. Holeck, J. A. Hoyle, O. E. Johannsson, B. F. Lantry, J. C. Makarewicz, E. S. Millard, I. F. Munawar, M. Munawar, R. O'Gorman, R. W. Owens, L. G. Rudstam, T. Schaner, and T. J. Stewart. 2003. Lake Ontario: food web dynamics in a changing ecosystem (1970-2000). Canadian Journal of Fisheries and Aquatic Sciences 60:471-490. http://dx.doi.org/10.1139/f03-033

Mitchell, P., and E. Prepas. 1990. Atlas of Alberta lakes. University of Alberta Press, Edmonton, Alberta, Canada.

Odum, E. P. 1969. The strategy of ecosystem development. Science 164:262-270. http://dx.doi.org/10.1126/science.164.3877.262

Opperman, J. J., and A. M. Merenlender. 2000. Deer herbivory as an ecological constraint to restoration of degraded riparian corridors. Restoration Ecology 8:41-47. http://dx.doi.org/10.1046/ j.1526-100x.2000.80006.x

Pauly, D., V. Christensen, and C. Walters. 2000. Ecopath, Ecosim, and Ecospace as tools for evaluating ecosystem impacts of fisheries. ICES Journal of Marine Science 57:697-706. http://dx. doi.org/10.1006/jmsc. 2000.0726

Persson, L., P.-A. Amundsen, A. M. De Roos, A. Klemetsen, R. Knudsen, and R. Primicerio. 2007. Culling prey promotes predator recovery - alternative states in a whole-lake experiment. Science 316:1743-1746. http://dx.doi.org/10.1126/science.1141412 
Petraitis, P. S., and S. R. Dudgeon. 2004. Detection of alternate stable states in marine communities. Journal of Experimental Marine Biology and Ecology 300:343-371. http://dx.doi. org/10.1016/j.jembe.2003.12.026

Rudstam, L. G., A. J. VanDeValk, C. M. Adams, J. T. H. Coleman, J. L. Forney, and M. E. Richmond. 2004. Cormorant predation and the population dynamics of walleye and yellow perch in Oneida Lake. Ecological Applications 14:149-163. http://dx.doi. org/10.1890/03-5010

Scheffer, M. 2009. Critical transitions in nature and society. Princeton University Press, Princeton, New Jersey, USA.

Scheffer, M., S. Carpenter, J. A. Foley, C. Folke, and B. Walker. 2001. Catastrophic shifts in ecosystems. Nature 413:591-596. http://dx.doi.org/10.1038/35098000

Schindler, D. W., A. P. Wolfe, R. Vinebrooke, A. Crowe, J. M. Blais, B. Miskimmin, R. Freed, and B. Perren. 2008. The cultural eutrophication of Lac la Biche, Alberta, Canada: a paleoecological study. Canadian Journal of Fisheries and Aquatic Sciences 65:2211-2223. http://dx. doi.org/10.1139/F08-117

Steinmetz, J., S. L. Kohler, and D. A. Soluk. 2003. Birds are overlooked top predators in aquatic food webs. Ecology 84:1324-1328. http://dx.doi.org/10.1890/0012-9658(2003)084[1324: BAOTPI]2.0.CO;2

Stewart, T. J., and W. G. Sprules. 2011. Carbon-based balanced trophic structure and flows in the offshore Lake Ontario food web before (1987-1991) and after (2001-2005) invasion-induced ecosystem change. Ecological Modelling 222:692-708. http://dx. doi.org/10.1016/j.ecolmodel.2010.10.024

Suding, K. N., K. L. Gross, and G. R. Houseman. 2004. Alternative states and positive feedbacks in restoration ecology. Trends in Ecology \& Evolution 19(1):46-53. http://dx.doi. org/10.1016/j.tree.2003.10.005

Van Auken, O. W. 2000. Shrub invasions of North American semiarid grasslands. Annual Review of Ecology and Systematics 31:197-215. http://dx.doi.org/10.1146/annurev.ecolsys.31.1.197

Walters, C., V. Christensen, and D. Pauly. 1997. Structuring dynamic models of exploited ecosystems from trophic massbalance assessment. Reviews in Fish Biology and Fisheries 7:139-172. http://dx.doi.org/10.1023/A:1018479526149

Walters, C., V. Christensen, W. Walters, and K. Rose. 2009. Representation of multi-stanza life histories in Ecospace models for spatial organization of ecosystem trophic interaction patterns. Bulletin of Marine Science 86:439-459.

Walters, C., and J. F. Kitchell. 2001. Cultivation/depensation effects on juvenile survival and recruitment: implications for the theory of fishing. Canadian Journal of Fisheries and Aquatic Sciences 58:39-50. http://dx.doi.org/10.1139/f00-160

Weseloh, D. V. C., C. Pekarik, T. Havelka, G. Barrett, and J. Reid. 2002. Population trends and colony locations of double-crested cormorants in the Canadian Great Lakes and immediately adjacent areas, 1990-2000: a manager's guide. Journal of Great Lakes Research 28:125-144. http://dx.doi.org/10.1016/S0380-1330 (02)70571-6
Wilson, J. B., and A. D. Q. Agnew. 1992. Positive-feedback switches in plant communities. Advances in Ecological Research 36:1013-1021.

Zimov, S. A., V. I. Chuprynin, A. P. Oreshko, F. S. Chapin, III, J. F. Reynolds, and M. C. Chapin. 1995. Steppe-tundra transition: a herbivore-driven biome shift at the end of the Pleistocene. American Naturalist 146:765-794. http://dx.doi.org/10.1086/285824 


\section{Appendix 1}

Table A1.1. Description of functional groups used in Ecopath models for Lac la Biche.

\begin{tabular}{|c|c|}
\hline Model group & Description \\
\hline WALL1 & Walleye (Sander vitreus) up to $50 \mathrm{~mm} \mathrm{TL}$ \\
\hline WALL2 & Walleye from 51 to $350 \mathrm{~mm} \mathrm{TL}$ \\
\hline WALL3 & Walleye $351 \mathrm{~mm}$ TL and larger \\
\hline NRPK1 & Northern pike (Esox lucius) up to $350 \mathrm{~mm}$ TL \\
\hline NRPK2 & Northern pike $351 \mathrm{~mm}$ TL and larger \\
\hline YLPR1 & Yellow perch (Perca flavescens) up to $100 \mathrm{~mm} \mathrm{TL}$ \\
\hline YPLR2 & Yellow perch from 101 to $200 \mathrm{~mm}$ TL \\
\hline YLPR3 & Yellow perch $201 \mathrm{~mm}$ TL and larger \\
\hline CISC1 & Cisco (Coregonus artedi) up to $140 \mathrm{~mm} \mathrm{TL}$ \\
\hline CISC2 & Cisco $141 \mathrm{~mm}$ TL and larger \\
\hline LKWH1 & Lake whitefish (Coregonus clupeaformis) up to $260 \mathrm{~mm}$ TL \\
\hline LKWH2 & Lake whitefish $261 \mathrm{~mm}$ TL and larger \\
\hline BURB1 & Burbot (Lota lota) up to $350 \mathrm{~mm} \mathrm{TL}$ \\
\hline BURB2 & Burbot $351 \mathrm{~mm}$ TL and larger \\
\hline Suckers & $\begin{array}{l}\text { White sucker (Catostomus commersonii) and longnose } \\
\text { sucker (Catostomus catostomus), all sizes. Mostly white } \\
\text { sucker. }\end{array}$ \\
\hline Sticklebacks & $\begin{array}{l}\text { Ninespine stickleback (Pungitius pungitius) and brook } \\
\text { stickleback (Culaea inconstans). Mostly ninespine } \\
\text { stickleback. }\end{array}$ \\
\hline Small Fish & $\begin{array}{l}\text { Spottail shiners (Notropis hudsonius), trout-perch } \\
\text { (Percopsis omiscomaycus), and lowa darters } \\
\text { (Etheostoma exile). Mostly spottail shiners. }\end{array}$ \\
\hline DCCO & Double-crested cormorant (Phalacrocorax auritus) \\
\hline AWPE & American white pelican (Pelecanus erythrorhynchus) \\
\hline Pisc. Birds & Piscivorous waterbirds \\
\hline Non-P. Birds & Non-piscivorous waterbirds \\
\hline
\end{tabular}


Chiro. \& Dip.

Amphi.

Mollusc \&

Gastro.

Inverts.

Litt. Zoopl.

Pel. Zoopl.

Cyano.

Phyto.

SAV
Chironomids and Dipterans

Amphipods

Molluscs and gastropods

All other aquatic invertebrates

Littoral zooplankton

Pelagic zooplankton

Cyanobacteria

Phytoplankton

Submerged aquatic vegetation including: macrophytes, periphytes, and epiphytes 
Table A1.2. Range of biomass $\left(\mathrm{t} \cdot \mathrm{km}^{-2}\right)$ values used in the balanced Ecopath models for each of the four modeled eras $(1800,1900,1965,2005)$.

Biomass $\left(\mathrm{t} / \mathrm{km}^{2}\right)$

Functional

Group

1800

1900

1965

2005

WALL1 stocked

WALL2 stocked

WALL3 stocked

WALL1

WALL2

WALL3

NRPK1

NRPK2

YLPR1

YLPR2

YLPR3

CISC1

CISC2

LKWH1

LKWH2

BURB1

BURB2

Suckers

Stickle.

Small Fishes

DCCO

AWPE

$$
\begin{gathered}
0.000-0.000 \\
0.099-0.247 \\
2.25-3.76
\end{gathered}
$$

$0.000-0.0002$

$0.101-0.801$

$2.24-3.77$

$0.000-0.000$

$0.019-0.019$

$0.169-0.169$

$0.030-0.057$

$0.024-0.089$

$1.42-8.70$

$0.000-0.000$

$0.001-0.015$

$0.006-0.061$

$0.000-0.003$

$0.000-0.048$

$0.000-0.210$

$1.90-5.01$

$0.011-0.079$

$0.013-0.102$

$0.623-2.66$

$0.910-2.00$

$0.793-4.48$

$0.764-4.66$

$0.993-2.37$

$0.963-5.97$

$0.495-10.4$

$0.382-2.87$

$0.533-3.94$

$0.451-5.43$

$0.539-20.0$

$1.10-7.60$

$0.900-8.60$

$0.38-1.67$

$0.331-2.29$

$0.254-0.765$

$1.50-6.00$

$0.096-10.5$

$3.50-10.5$

$4.04-18.00$

$$
0.654-2.06
$$

$0.301-2.55$

$0.124-2.22$

$0.900-5.41$

$0.656-9.37$

$4.63-10.6$

$6.50-13.8$

$2.53-12.6$

$$
\begin{gathered}
0.122-0.431 \\
0.650-2.43
\end{gathered}
$$

$0.140-0.853$

$0.087-0.265$

$0.307-0.948$

$0.113-0.469$

$0.841-1.10$

$0.726-3.00$

$2.50-6.50$

$$
2.01-6.58
$$

$3.50-8.20$

$0.178-0.620$

$0.801-2.90$

$0.865-5.20$

$0.329-1.27$

$1.10-3.50$

$0.325-2.15$

$0.322-2.65$

$0.069-1.00$

$1.00-3.13$

$0.210-0.210$

$0.210-0.073$

$0.006-0.009$

$0.102-1.08$

$0.005-0.005$

$0.006-0.009$

$0.290-0.309$

$0.006-0.040$ 


$\begin{array}{lcccc}\text { Pisc. Birds } & 0.004-0.006 & 0.004-0.006 & 0.003-0.003 & 0.008-0.008 \\ \text { Non-Pisc. Birds } & 0.010-0.014 & 0.010-0.014 & 0.011-0.011 & 0.019-0.019 \\ \text { Chiro. \& Dip. } & 5.19-25.00 & 5.00-25.0 & 7.13-24.9 & 3.96-40.4 \\ \text { Amphi. } & 0.906-4.00 & 0.901-4.20 & 0.774-4.99 & 1.60-8.96 \\ \text { Molluscs \& } & 1.19-4.00 & 1.21-4.22 & 0.768-4.08 & 0.553-46.6 \\ \text { Gastro. } & 0.973-4.00 & 0.978-4.35 & 0.580-3.85 & 1.23-32.9 \\ \text { Other Inverts } & 0.357-1.40 & 0.349-0.358 & 0.380-0.392 & 0.374-0.374 \\ \text { Litt. Zoopl. } & 0.154-5.00 & 0.139-5.00 & 0.259-3.85 & 0.120-7.51 \\ \text { Pel. Zoopl. } & 2.18-4.36 & 2.18-4.36 & 2.16-4.48 & 4.48-8.72 \\ \text { Cyanobacteria } & 3.18-6.36 & 3.18-6.38 & 3.15-5.24 & 5.92-12.0 \\ \text { Phytoplankton } & 0.311-115 & 0.312-115 & 0.266-115 & 0.128-115 \\ \text { Macrophytes } & 0.500-0.500 & 0.005-0.500 & 0.005-0.600 & 0.005-10.0 \\ \text { Detritus } & & & & \\ & & & & \end{array}$


Table A1.3. Range of production/biomass (year ${ }^{-1}$ ) values used in the balanced Ecopath models for each of the four modeled eras $(1800,1900,1965,2005)$.

Production/Biomass ( /year)

Functional

Group

1800

1900

1965

2005

WALL1 stocked

5.5

6.00

WALL2 stocked

0.6

2.40

WALL3 stocked

0.25

0.40

WALL1

$4.90-11.20$

$2.80-13.00$

$5.00-11.00$

$6.00-16.00$

WALL2

$0.73-0.95$

$0.60-0.90$

$0.60-0.90$

$0.65-2.00$

WALL3

$0.17-0.25$

$0.20-0.31$

$0.25-0.45$

$0.25-0.72$

NRPK1

$1.25-1.40$

$0.65-1.33$

$0.65-1.40$

$0.65-2.80$

NRPK2

$0.15-0.27$

$0.21-0.27$

$0.27-0.40$

$0.25-0.40$

YLPR1

$2.60-5.25 \quad 2.60-5.00$

$2.30-3.25$

$1.70-8.00$

YLPR2

$0.96-2.00$

$0.82-1.92$

$0.77-2.19$

$1.25-2.83$

YLPR3

$0.45-0.60$

$0.46-0.60$

$0.42-0.65$

$0.40-1.31$

CISC1

$1.89-2.30$

$1.40-2.40$

$1.60-2.75$

$1.60-3.35$

CISC2

$0.53-0.60$

$0.50-0.65$

$0.65-0.90$

$0.62-1.50$

LKWH1

$0.90-2.00 \quad 0.90-2.00$

$1.50-2.00$

$1.30-2.00$

LKWH2

$0.30-0.46$

$0.30-0.68$

$0.30-0.60$

$0.40-0.53$

BURB1

$0.65-1.00$

$0.83-0.94$

$0.8-1.50$

$0.75-1.75$

BURB2

$0.29-0.31$

$0.29-0.31$

$0.30-0.40$

$0.26-0.43$

Suckers

$0.30-0.38$

$0.30-0.41$

$0.30-0.41$

$0.30-0.85$

Stickle.

Small Fishes

$2.75-3.00$

$2.75-3.00$

$3.00-3.20$

$1.90-3.15$

1.71

$1.71-2.00$

$1.85-2.00$

$1.60-2.50$

0.52

$0.45-0.56$

0.52

0.52

AWPE

$0.19-0.20$

$0.19-0.20$

$0.19-0.20$ 


$\begin{array}{lcccc}\text { Pisc. Birds } & 0.25 & 0.25 & 0.25 & 0.25 \\ \text { Non-Pisc. Birds } & 0.25 & 0.25 & 0.25 & 0.25 \\ \text { Chiro. \& Dip. } & 13.1 & 13.1 & 13.1 & 13.10-18.00 \\ \text { Amphi. } & 5.7 & 5.70-6.60 & 5.70-6.60 & 5.70-8.76 \\ \text { Molluscs \& } & & & & \\ \text { Gastro. } & 3.8 & 3.00-3.80 & 3.00-3.80 & 3.00-6.11 \\ \text { Other Inverts } & 5.35 & 4.63-5.35 & 4.63-5.35 & 4.63-7.35 \\ \text { Litt. Zoopl. } & 35 & 35.00-37.00 & 35 & 35.00 \\ \text { Pel. Zoopl. } & 35 & 32.00-44.00 & 32.00-40.00 & 32.00 \\ \text { Cyanobacteria } & 131.5 & 131.5 & 131.5-200.0 & 131.5-200.0 \\ \text { Phytoplankton } & 131.5 & 131.5-176.0 & 176.0-200.0 & 131.5-200.0 \\ \text { Macrophytes } & 8.80-20.0 & 8.80-20.00 & 8.80-20.00 & 8.80-20.00\end{array}$


Table A1.4. Range of consumption/biomass (year ${ }^{-1}$ ) values used in the balanced Ecopath models for each of the four modeled eras (1800, 1900, 1965, 2005).

\begin{tabular}{|c|c|c|c|c|}
\hline \multirow{2}{*}{$\begin{array}{l}\text { Functional } \\
\text { Group }\end{array}$} & \multicolumn{4}{|c|}{ Consumption/Biomass ( /year) } \\
\hline & 1800 & 1900 & 1965 & 2005 \\
\hline WALL1 stocked & & & 49.45 & 45.34 \\
\hline WALL2 stocked & & & 4.26 & 6.39 \\
\hline WALL3 stocked & & & 1.85 & 1.85 \\
\hline WALL1 & $73.43-88.20$ & $48.16-87.98$ & $45.03-70.14$ & 103.38 \\
\hline WALL2 & $5.40-6.57$ & $4.26-6.54$ & $3.35-4.26$ & 11.38 \\
\hline WALL3 & $1.50-1.95$ & $1.50-1.95$ & $1.50-1.85$ & $1.50-3.64$ \\
\hline NRPK1 & $7.20-8.94$ & $6.27-8.94$ & $5.44-6.49$ & $3.87-12.51$ \\
\hline NRPK2 & $1.40-1.95$ & $1.40-1.95$ & $1.40-1.90$ & $1.40-3.00$ \\
\hline YLPR1 & $11.67-16.70$ & $11.73-18.72$ & $11.00-19.54$ & $9.01-52.34$ \\
\hline YLPR2 & $4.56-6.75$ & $4.45-6.68$ & $4.38-8.16$ & $3.86-14.20$ \\
\hline YLPR3 & $2.74-3.57$ & $2.84-3.57$ & $2.84-3.50$ & $1.46-5.00$ \\
\hline CISC1 & $11.15-12.97$ & $10.44-14.41$ & $10.19-11.97$ & $9.25-18.79$ \\
\hline CISC2 & $3.65-3.69$ & $3.65-4.00$ & $3.60-4.00$ & $3.69-6.42$ \\
\hline LKWH1 & $5.41-11.60$ & $5.16-12.13$ & $5.43-12.13$ & $5.71-10.80$ \\
\hline LKWH2 & $2.35-2.85$ & $2.35-3.00$ & $2.35-3.00$ & $2.35-3.00$ \\
\hline BURB1 & $4.24-6.34$ & $4.02-6.14$ & $4.02-6.30$ & $3.65-11.27$ \\
\hline BURB2 & $1.90-2.22$ & $1.90-2.22$ & $1.95-2.00$ & $1.95-3.30$ \\
\hline Suckers & $2.25-2.26$ & $2.25-3.80$ & $2.26-3.80$ & $2.26-3.80$ \\
\hline Stickle. & $9.53-11.28$ & $9.53-14.00$ & $10.50-14.0$ & $6.30-14.00$ \\
\hline Small Fishes & $6.42-8.66$ & $6.42-10.00$ & $8.66-10.00$ & $6.38-10.00$ \\
\hline DCCO & 72.9 & 72.9 & 72.9 & 72.9 \\
\hline AWPE & 110 & 110 & 110 & 110 \\
\hline
\end{tabular}




\begin{tabular}{lcccc} 
Pisc. Birds & 58 & 58 & 58 & 58 \\
Non-Pisc. Birds & 58 & 58 & 58 & 58 \\
Chiro. \& Dip. & 62.4 & 62.4 & 62.4 & $62.40-65.85$ \\
Amphi. & 30.2 & 30.2 & 30.2 & $27.20-30.20$ \\
Molluscs \& & & & & \\
Gastro. & 24.4 & 24.4 & 24.4 & $21.40-24.40$ \\
Other Inverts & 31.8 & 31.8 & 31.8 & $24.00-31.80$ \\
Litt. Zoopl. & 120 & 120 & 120 & 120 \\
Pel. Zoopl. & 120 & $120.00-150.00$ & 120 & $113.00-176.00$ \\
\hline
\end{tabular}


Table A1.5. Range of ecotrophic efficiency values used in the balanced Ecopath models for each of the four modeled time periods (1800, 1900, 1965, 2005).

\begin{tabular}{|c|c|c|c|c|}
\hline \multirow{2}{*}{$\begin{array}{l}\text { Functional } \\
\text { Group }\end{array}$} & \multicolumn{4}{|c|}{ Ecotropic Efficiency } \\
\hline & 1800 & 1900 & 1965 & 2005 \\
\hline WALL1 stocked & & & $0.98-0.99$ & 0.98 \\
\hline WALL2 stocked & & & $0.36-0.68$ & 0.94 \\
\hline WALL3 stocked & & & 1 & 0.67 \\
\hline WALL1 & $0.91-1.00$ & $0.48-0.99$ & $0.56-0.99$ & $0.00-0.98$ \\
\hline WALL2 & $0.32-0.96$ & $0.37-0.99$ & $0.50-0.99$ & $0.18-1.00$ \\
\hline WALL3 & $0.01-0.12$ & $0.06-0.93$ & $0.35-0.99$ & $0.08-0.90$ \\
\hline NRPK1 & $0.56-1.00$ & $0.55-0.95$ & $0.22-0.68$ & $0.74-0.99$ \\
\hline NRPK2 & $0.02-0.28$ & $0.16-0.99$ & $0.08-0.89$ & $0.10-0.18$ \\
\hline YLPR1 & $0.90-1.00$ & $0.85-1.00$ & $0.21-0.98$ & $0.09-0.92$ \\
\hline YLPR2 & $0.57-0.98$ & $0.62-0.99$ & $0.04-0.53$ & $0.05-1.00$ \\
\hline YLPR3 & $0.47-0.90$ & $0.45-0.91$ & $0.31-0.98$ & $0.06-0.98$ \\
\hline CISC1 & $0.95-1.00$ & $0.57-0.99$ & $0.20-0.55$ & $0.14-0.99$ \\
\hline CISC2 & $0.90-0.96$ & $0.60-1.00$ & $0.92-0.98$ & $0.23-0.99$ \\
\hline LKWH1 & 0.63-0.99 & $0.35-1.00$ & $0.21-0.93$ & $0.21-0.97$ \\
\hline LKWH2 & $0.17-0.83$ & $0.59-0.99$ & $0.22-0.96$ & $0.68-0.95$ \\
\hline BURB1 & $0.68-0.99$ & $0.54-0.94$ & $0.24-0.99$ & $0.47-0.98$ \\
\hline BURB2 & $0.01-0.76$ & $0.02-0.37$ & $0.38-0.93$ & $0.44-0.78$ \\
\hline Suckers & $0.46-0.69$ & $0.42-1.00$ & $0.12-0.59$ & $0.22-0.99$ \\
\hline Stickle. & $0.97-0.99$ & 0.84-0.99 & $0.69-0.99$ & $0.64-0.99$ \\
\hline Small Fishes & 0.95 & $0.55-0.99$ & $0.71-0.97$ & $0.69-0.97$ \\
\hline DCCO & $0.00-0.09$ & $0.00-0.10$ & $0.00-0.34$ & $0.00-0.01$ \\
\hline AWPE & 0.00 & 0.00 & 0.00 & 0.00 \\
\hline
\end{tabular}


Pisc. Birds

$\begin{array}{cccc}0.00 & 0.00 & 0.00 & 0.00 \\ 0.00 & 0.00 & 0.00 & 0.00-0.58 \\ 0.16-0.80 & 0.14-0.91 & 0.20-0.50 & 0.09-0.95 \\ 0.68-0.95 & 0.70-0.98 & 0.63-0.83 & 0.60-0.95 \\ & & & \\ 0.35-0.90 & 0.17-0.97 & 0.09-0.70 & 0.08-0.95 \\ 0.49-0.95 & 0.61-0.96 & 0.60-0.80 & 0.60-0.99 \\ 0.90-0.95 & 0.88-0.95 & 0.91-0.95 & 0.34-0.72 \\ 0.72-0.99 & 0.86-1.00 & 0.32-0.94 & 0.40-0.99 \\ 0.01-0.16 & 0.01-0.16 & 0.01-0.08 & 0.00-0.12 \\ 0.24-0.95 & 0.23-1.00 & 0.36-0.93 & 0.16-0.96 \\ 0.10-0.13 & 0.10-0.13 & 0.10-0.13 & 0.10-0.21 \\ 0.24-0.83 & 0.23-0.82 & 0.25-0.73 & 0.11-0.75\end{array}$

Non-Pisc. Birds

Chiro. \& Dip.

Amphi.

Molluscs \&

Gastro.

Other Inverts

Litt. Zoopl.

Pel. Zoopl.

Cyanobacteria

Phytoplankton

Macrophytes

Detritus 
Table A1.6. Range in multistanza ages (months) and von Bertalanffy K ( /year) values used to describe the dynamics of the multistanza groups in the balanced Ecopath models for each of the four modeled eras $(1800,1900,1965,2005)$. The multistanza age represents the number of months of age at which fish in one functional group transition to the next older group. For example, WALL1 individuals transition to WALL2 at 3 months old.

\begin{tabular}{|c|c|c|c|c|}
\hline $\begin{array}{l}\text { Functiona } \\
\text { I Group }\end{array}$ & 1800 & 1900 & 1965 & 2005 \\
\hline & \multicolumn{4}{|c|}{ Multistanza Age (Months) } \\
\hline WALL1 & 0 & 0 & 0 & 0 \\
\hline WALL2 & 3 & 3 & $2-3$ & $3-4$ \\
\hline WALL3 & $39-40$ & $39-40$ & $36-39$ & $36-42$ \\
\hline NRPK1 & 0 & 0 & 0 & 0 \\
\hline NRPK2 & $16-26$ & $16-26$ & $22-24$ & $15-24$ \\
\hline YLPR1 & 0 & 0 & 0 & 0 \\
\hline YLPR2 & $15-18$ & $14-18$ & $14-18$ & $8-23$ \\
\hline YLPR3 & $33-52$ & $33-52$ & $48-52$ & $30-75$ \\
\hline CISC1 & 0 & 0 & 0 & 0 \\
\hline CISC2 & $18-20$ & $16-20$ & $16-20$ & $18-24$ \\
\hline LKWH1 & 0 & 0 & 0 & 0 \\
\hline LKWH2 & $26-34$ & $22-34$ & $26-30$ & $26-30$ \\
\hline BURB1 & 0 & 0 & 0 & 0 \\
\hline \multirow[t]{2}{*}{ BURB2 } & $42-48$ & $37-48$ & $37-48$ & $42-48$ \\
\hline & \multicolumn{4}{|c|}{ von Bertalanffy K ( /year) } \\
\hline WALL & 0.1 & $0.10-0.21$ & $0.150-0.206$ & $0.10-0.22$ \\
\hline NRPK & $0.109-0.270$ & $0.101-0.270$ & $0.101-0.200$ & $0.101-0.270$ \\
\hline YLPR & $0.201-0.307$ & $0.20-0.36$ & $0.201-0.307$ & $0.070-0.307$ \\
\hline CISC & $0.20-0.27$ & $0.2-0.3$ & $0.26-0.35$ & $0.27-0.36$ \\
\hline
\end{tabular}


LKWH

0.149-0.283

0.156-0.300

$0.156-0.283$

$0.145-0.283$

BURB

$0.115-0.200$

0.115-0.33

0.115-0.327

0.115-0.3 
Table A1.7. Range in fishery catches $\left(\mathrm{t} \cdot \mathrm{km}^{-2} \cdot \mathrm{yr}^{-1}\right)$ used in the balanced Ecopath models for each of the four modeled eras $(1800,1900,1965,2005)$.

\begin{tabular}{|c|c|c|c|c|}
\hline \multirow{2}{*}{$\begin{array}{l}\text { Functional } \\
\text { Group }\end{array}$} & \multicolumn{4}{|c|}{ Fisheries Catches $\left(X 10^{-2}\right)\left(\mathrm{t} \cdot \mathrm{km}^{-2} \cdot \mathrm{yr}^{-1}\right)$} \\
\hline & 1800 & 1900 & 1965 & 2005 \\
\hline WALL3 & $0.86-5.90$ & $5.56-16.99$ & $0.045-5.56$ & $0.0013-0.43$ \\
\hline NRPK2 & $1.42-38.00$ & $12.00-32.50$ & $5.75-30.31$ & $4.58-5.54$ \\
\hline YLPR3 & $0.40-0.73$ & $0.67-1.10$ & $0.67-134.47$ & $0.15-1.60$ \\
\hline CISC2 & $0.25-0.40$ & $0.27-1.60$ & $0.51-300.00$ & $0.21-12.72$ \\
\hline LKWH2 & $14.20-163.80$ & $73.37-165.00$ & $40.00-183.50$ & $23.29-28.03$ \\
\hline BURB2 & $0.50-4.88$ & $2.01-5.42$ & $2.010-26.68$ & $0.048-4.50$ \\
\hline Suckers & $1.37-7.00$ & $2.60-28.50$ & $2.26-11.85$ & $0.36-3.74$ \\
\hline DCCO & $<<0.1-0.1$ & $0.010-0.37$ & $<<0.10-0.10$ & $0.010-0.10$ \\
\hline
\end{tabular}




\section{Appendix 2}

Figure A2.1 - Ecopath flow diagram illustrating the trophic linkages between all functional groups in a representative model of the ecosystem in 1800. Circle size is representative of each groups' biomass and circles are positioned based on the non-integer trophic levels (numbers along the left side). For a description of each functional group see Table A1.1.

5

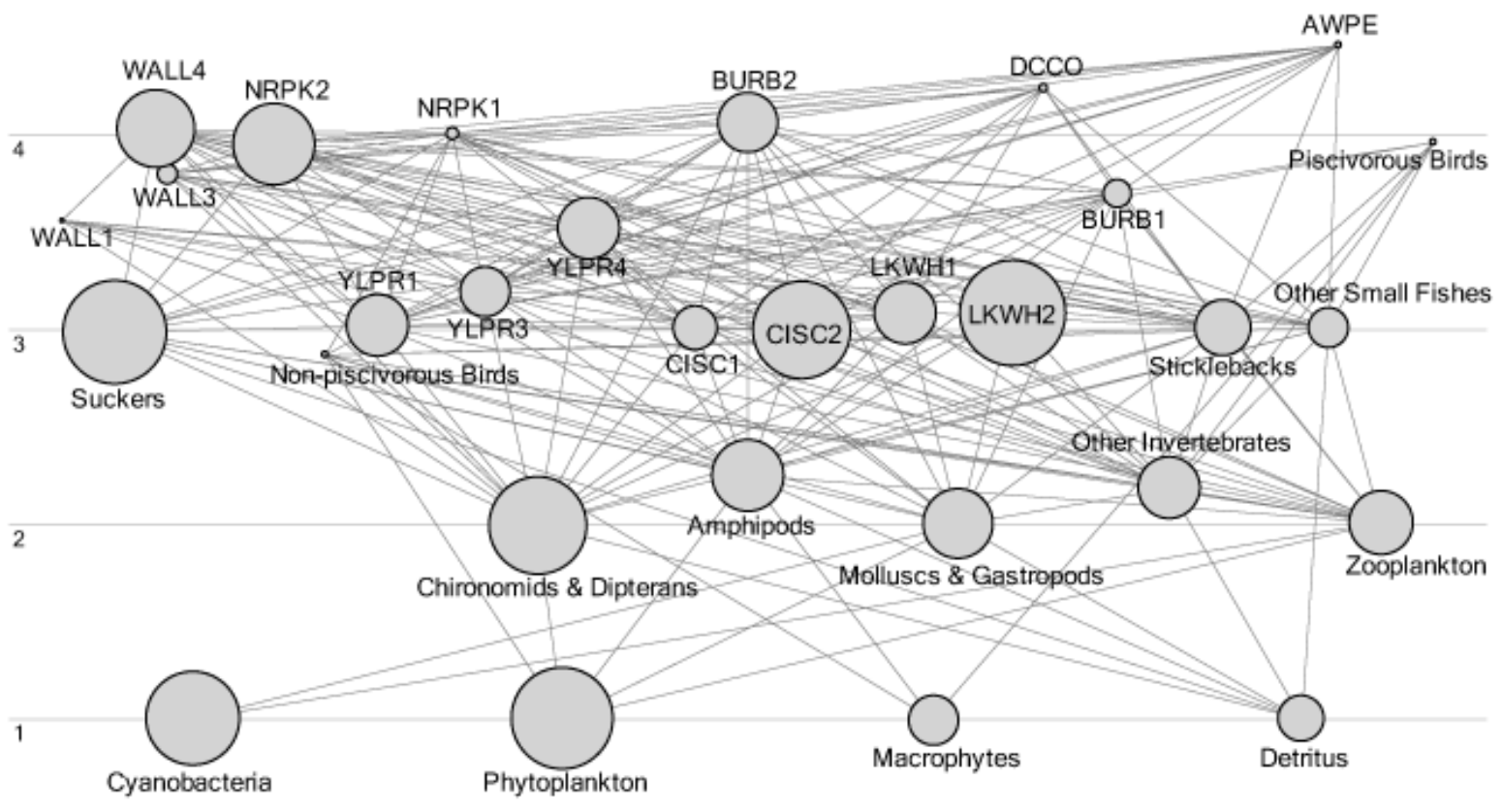


Figure A2.2 - Ecopath flow diagram illustrating the trophic linkages between all functional groups in a representative model of the ecosystem in 1900. Circle size is representative of each groups' biomass and circles are positioned based on the non-integer trophic levels (numbers along the left side). For a description of each functional group see Table A1.1.

5

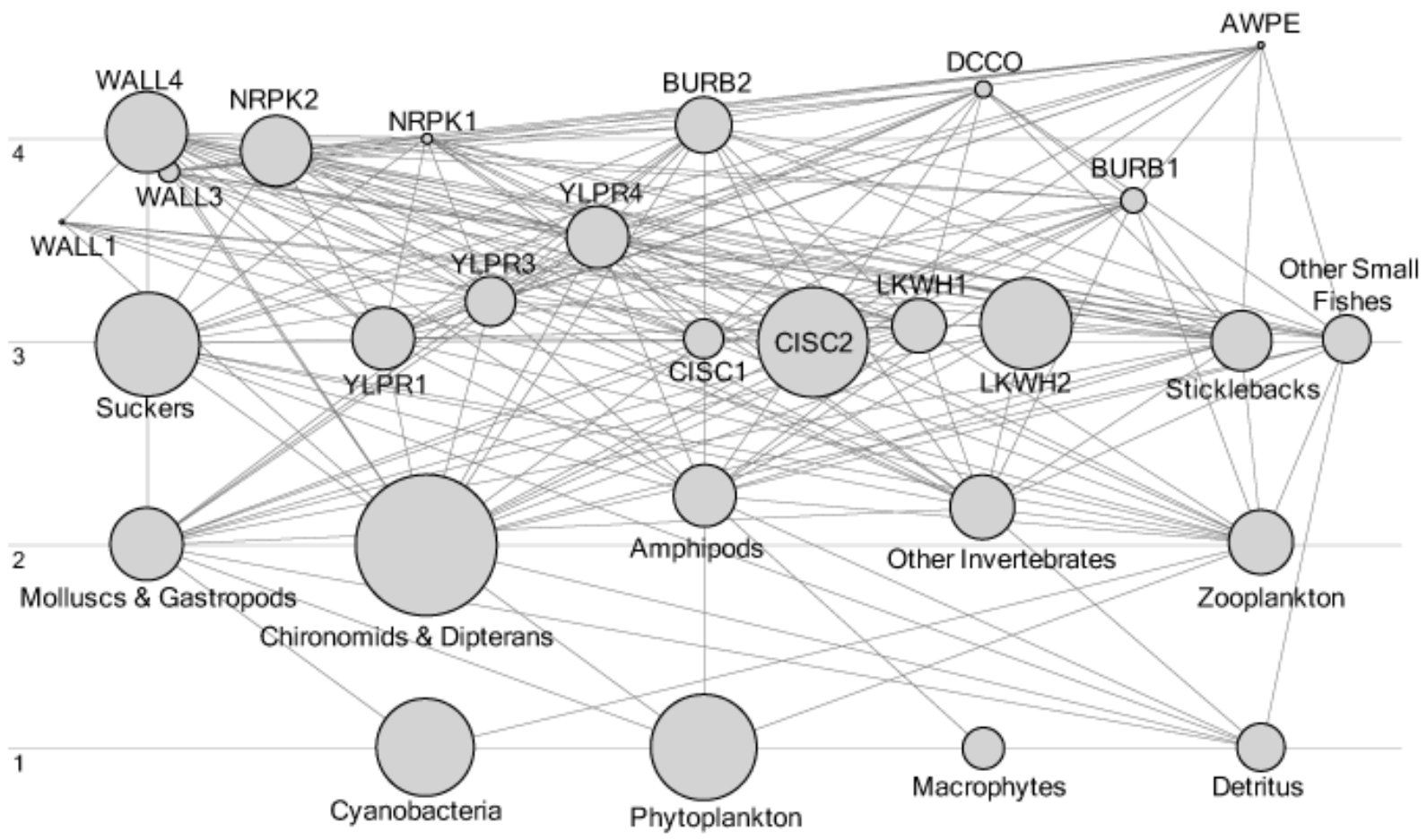


Figure A2.3 - Ecopath flow diagram illustrating the trophic linkages between all functional groups in a representative model of the ecosystem in 1965. Circle size is representative of each groups' biomass and circles are positioned based on the non-integer trophic levels (numbers along the left side). For a description of each functional group see Table A1.1.

5

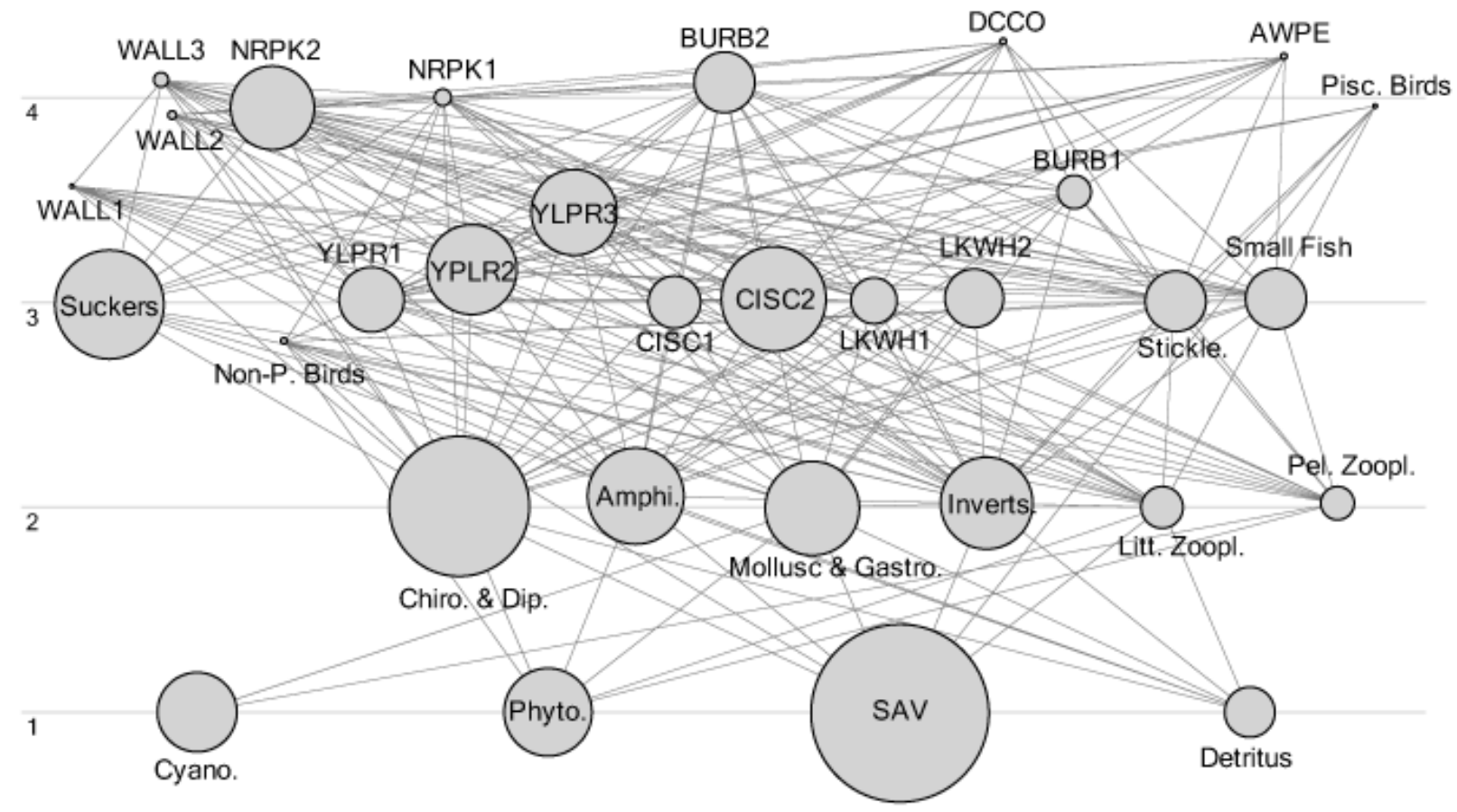


Figure A2.4 - Ecopath flow diagram illustrating the trophic linkages between all functional groups in a representative model of the ecosystem in 2005. Circle size is representative of each groups' biomass and circles are positioned based on the non-integer trophic levels (numbers along the left side). For a description of each functional group see Table A1.1.

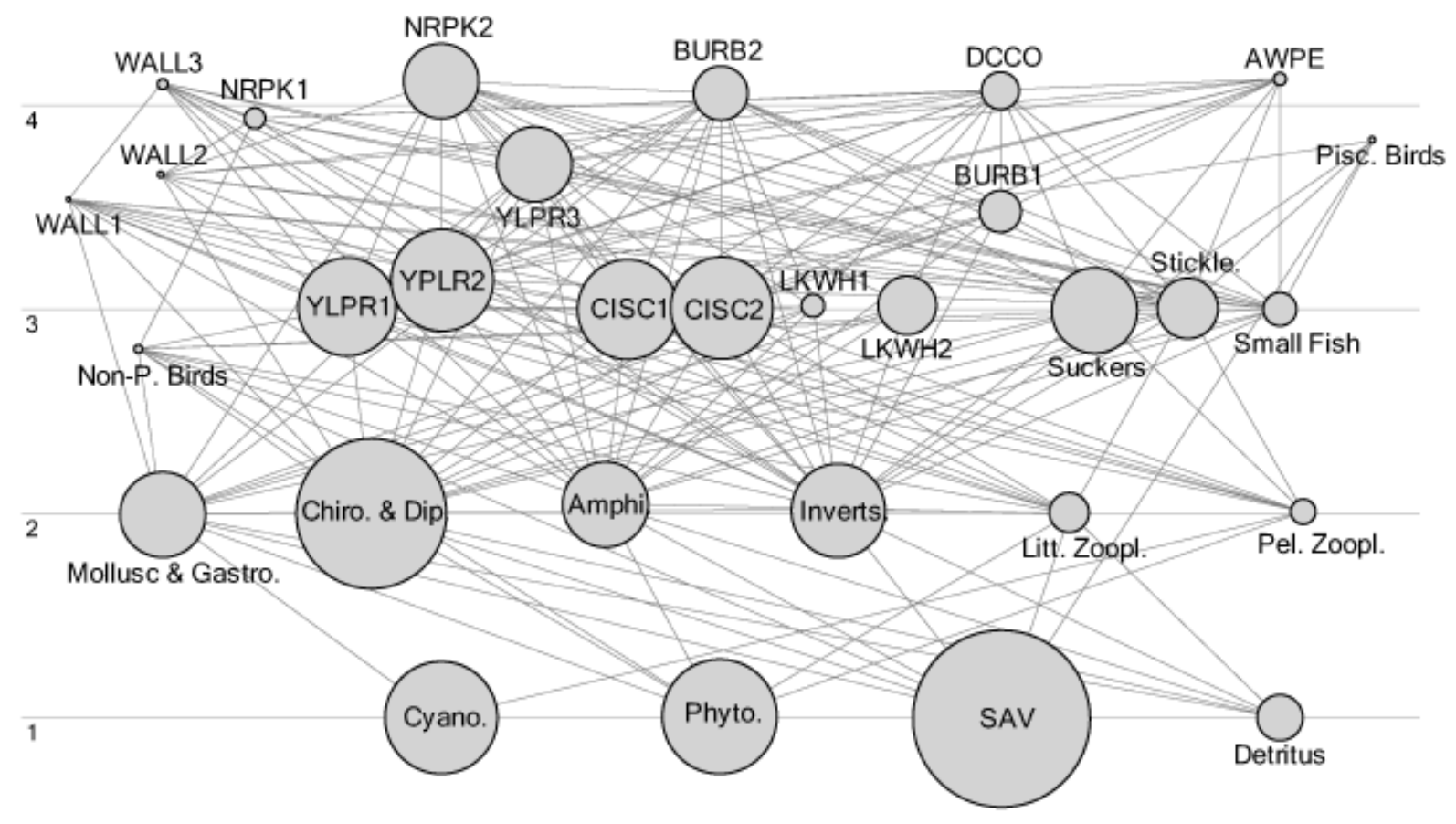

